Prepared for the National Aeronautics and Space Administration

\title{
Geologic Map of the Snegurochka Planitia Quadrangle (V-1), Venus
}

By Debra M. Hurwitz and James W. Head

Pamphlet to accompany

Scientific Investigations Map 3178 
This page intentionally left blank 


\section{Contents}

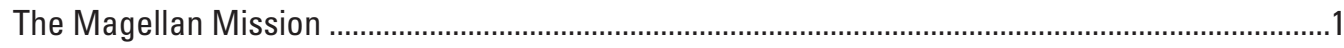

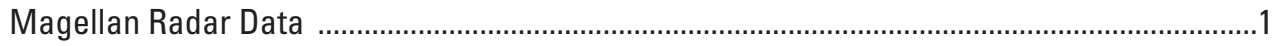

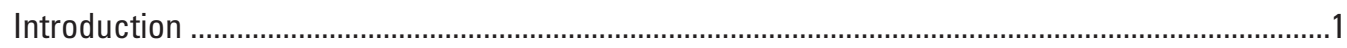

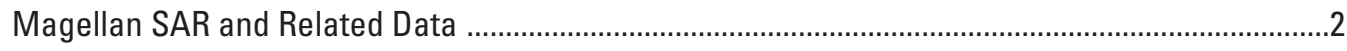

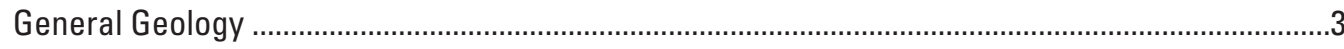

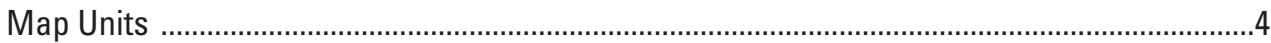

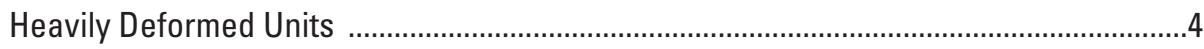

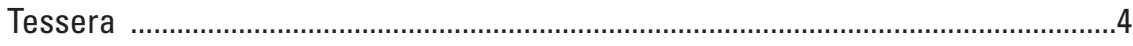

Densely Lineated Plains Material ..........................................................................

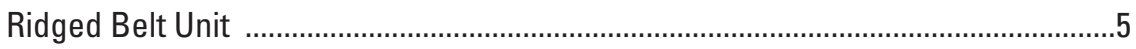

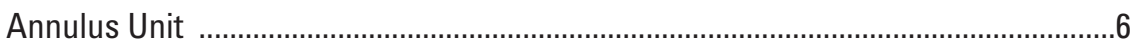

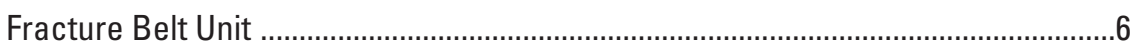

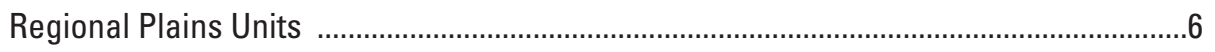

Dark Deformed Plains Material ...............................................................................

Bright Deformed Plains Material .........................................................................6

Dark Smooth Plains Material ..............................................................................

Bright Smooth Plains Material .............................................................................

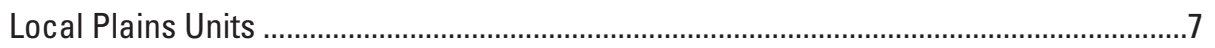

Shield Plains Units ................................................................................................

Bright Deformed Corona Plains Material ..................................................................

Dark Smooth Corona Plains Material .......................................................................

Bright Smooth Corona Plains Material ..................................................................

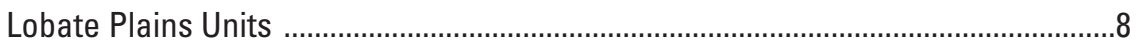

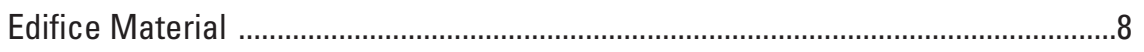

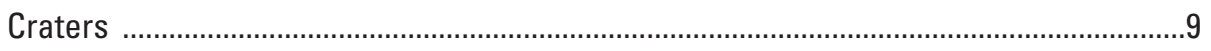

Undifferentiated Crater Material ............................................................................

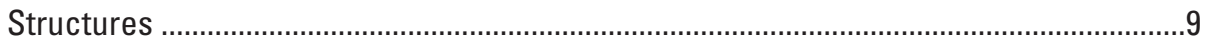

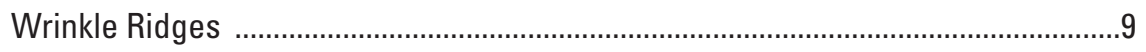

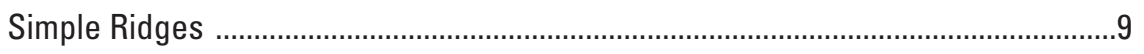

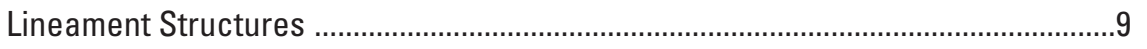

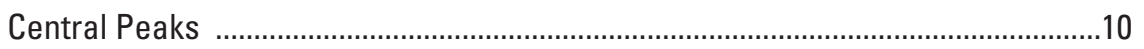

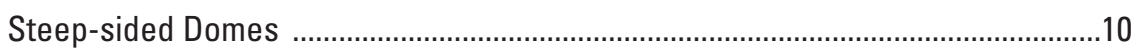

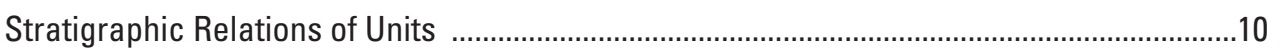

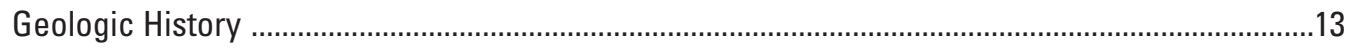

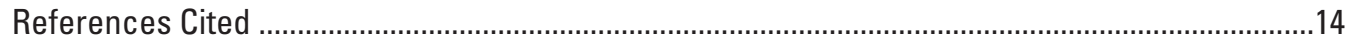

\section{Tables}

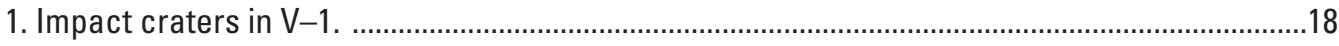

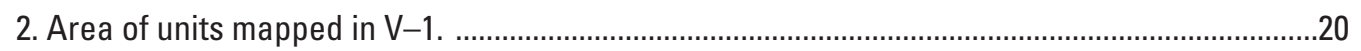

\section{Figures}

1. Magellan synthetic aperture radar (SAR) data for Snegurochka Planitia, V-1, Venus, from lat $75^{\circ} \mathrm{N}$. to $90^{\circ} \mathrm{N}$., and geologic sketch of the $\mathrm{V}-1$ region with major tectonic and volcanic features labeled

2. Magellan altimetry data with $10-30 \mathrm{~km}$ horizontal resolution and $80-100 \mathrm{~m}$ vertical resolution (map sheet) 
3. A, Venera 15/16 data fill in gaps in Magellan data; B, Geologic map based on observations made using Venera 15/16 data (Venus Venera 15/16 atlas, Kotelnikov and others, 1989); C, Geologic map based on observations made using Magellan data (map sheet)

4. A representation of identified structures within Snegurochka Planitia, V-1, including lineaments, wrinkle ridges, simple ridges, and small shield volcanoes (map sheet)

5. Asymmetric lobate plains associated with Sarasvati Mons and Heloha Fluctus near the boundary between Snegurochka Planitia and Itzpapalotl Tessera (map sheet)

6. Impact craters found in Snegurochka Planitia, V-1 (map sheet)

7. Regional plains near Klenova crater that have been extensively deformed by wrinkle ridges 22

8. Spatial distributions of unit classes identified within V-1 (map sheet)

9. Examples of the heavily deformed units described in the text

10. Topographic profiles of three ridged belts observed in $V-1$, with the extent of each belt represented in bold on each profile

11. Topographic profiles of three fracture belts observed in $\mathrm{V}-1$, with the extent of each belt represented in bold on each profile

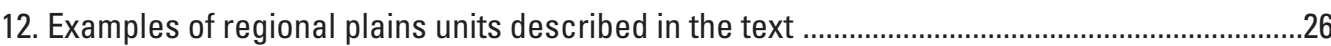

13. Examples of localized plains units described in the text ....................................................27

14. Examples of the stratigraphy of small shield volcanoes observed in $\mathrm{V}-1$ (map sheet)

15. Examples of structures described in the text

16. Stratigraphic relations of tessera (map sheet)

17. Stratigraphic relations of densely lineated plains unit pdl (map sheet)

18. Stratigraphic relations of fractures associated with Anahit Corona (left of image) and Pomona Corona (lower right of image) (map sheet)

19. Stratigraphic relations of the ridged belt unit rb (map sheet)

20. Stratigraphic relations of regional plains units pdd, pbd, pds, and pbs (map sheet)

21. Stratigraphic relations of individual shield volcanoes and shield plains units $\mathrm{psh}_{1}$ and $\mathrm{psh}_{2}$ (map sheet)

22. Stratigraphic relations of fracture belts (unit fb) (map sheet)

23. Stratigraphic relations of lobate plains (unit pla) (map sheet) 


\section{The Magellan Mission}

The Magellan spacecraft orbited Venus from August 10, 1990, until it plunged into the Venusian atmosphere on October 12, 1994. Magellan Mission objectives included (1) improving the knowledge of the geological processes, surface properties, and geologic history of Venus by analysis of surface radar characteristics, topography, and morphology and (2) improving the knowledge of the geophysics of Venus by analysis of Venusian gravity.

The Magellan spacecraft carried a $12.6-\mathrm{cm}$ radar system to map the surface of Venus. The transmitter and receiver systems were used to collect three data sets: (1) synthetic aperture radar (SAR) images of the surface, (2) passive microwave thermal emission observations, and (3) measurements of the backscattered power at small angles of incidence, which were processed to yield altimetric data. Radar imaging and altimetric and radiometric mapping of the Venusian surface were accomplished in mission cycles 1, 2, and 3 from September 1990 until September 1992. Ninety-eight percent of the surface was mapped with radar resolution on the order of $120 \mathrm{~m}$. The SAR observations were projected to a 75-m nominal horizontal resolution, and these full-resolution data compose the image base used in geologic mapping. The primary polarization mode was horizontal-transmit, horizontal-receive $(\mathrm{HH})$, but additional data for selected areas were collected for the vertical polarization sense. Incidence angles varied between about $20^{\circ}$ and $45^{\circ}$.

High-resolution Doppler tracking of the spacecraft took place from September 1992 through October 1994 (mission cycles 4, 5, 6). Approximately 950 orbits of high-resolution gravity observations were obtained between September 1992 and May 1993 while Magellan was in an elliptical orbit with a periapsis near $175 \mathrm{~km}$ and an apoapsis near 8,000 km. An additional 1,500 orbits were obtained following orbit-circularization in mid-1993. These data exist as a $75^{\circ}$ by $75^{\circ}$ harmonic field.

\section{Magellan Radar Data}

Radar backscatter power is determined by (1) the morphology of the surface at a broad range of scales and (2) the intrinsic reflectivity, or dielectric constant, of the material. Topography at scales of several meters and larger can produce quasi-specular echoes, and the strength of the return is greatest when the local surface is perpendicular to the incident beam. This type of scattering is most important at very small angles of incidence, because natural surfaces generally have few large tilted facets at high angles. The exception is in areas of steep slopes, such as ridges or rift zones, where favorably tilted terrain can produce very bright signatures in the radar image. For most other areas, diffuse echoes from roughness at scales comparable to the radar wavelength are responsible for variations in the SAR return. In either case, the echo strength is also modulated by the reflectivity of the surface material. The density of the upper few wavelengths of the surface can have a significant effect. Low-density layers, such as crater ejecta or volcanic ash, can absorb the incident energy and produce a lower observed echo. On Venus, a rapid increase in reflectivity exists at a certain critical elevation above which high-dielectric minerals or coatings are thought to be present. This leads to very bright SAR echoes from virtually all areas above that critical elevation.

The measurements of passive thermal emission from Venus, though of much lower spatial resolution than the SAR data, are more sensitive to changes in the dielectric constant of the surface than to roughness. They can be used to augment studies of the surface and to discriminate between roughness and reflectivity effects. Observations of the near-nadir backscatter power, collected using a separate smaller antenna on the spacecraft, were modeled using the Hagfors expression for echoes from gently undulating surfaces to yield estimates of planetary radius, Fresnel reflectivity, and root-mean-square (rms) slope. The topographic data produced by this technique have horizontal footprint sizes of about $10 \mathrm{~km}$ near periapsis and a vertical resolution on the order of $100 \mathrm{~m}$. The Fresnel reflectivity data provide a comparison to the emissivity maps, and the rms slope parameter is an indicator of the surface tilts, which contribute to the quasi-specular scattering component.

\section{Introduction}

The Snegurochka Planitia region (V-1 quadrant, fig. 1A) is a predominantly low-lying terrain that covers the north polar region of Venus, extending from lat $75^{\circ} \mathrm{N}$. to $90^{\circ} \mathrm{N}$. and from long $0^{\circ} \mathrm{E}$. to $360^{\circ} \mathrm{E}$. The plains associated with Snegurochka Planitia (fig. $1 B$ ) abut the highlands of Metis Mons to the south from approximately long $240^{\circ} \mathrm{E}$. to $300^{\circ} \mathrm{E}$. (V-6) and the highlands of Ishtar Terra to the south from approximately long $300^{\circ}$ E. to $60^{\circ}$ E. (Lakshmi Planum, V-7; Fortuna Tessera, V-2). The plains of Louhi Planitia also lie within the $\mathrm{V}-1$ region and form the northern border with the highlands of Tethus Regio from approximately long $60^{\circ} \mathrm{E}$. to $120^{\circ} \mathrm{E}$. (V-3 Meskhent Tessera, Ivanov and Head, 2008) and with the lowlands of both Atalanta Planitia (V-4, Ivanov and Head, 2004b) and the nearby deformed region containing a series of ridged belts (V-5, Pandrosos Dorsa, Rosenberg and McGill, 2001) from approximately long $120^{\circ} \mathrm{E}$. to $240^{\circ} \mathrm{E}$. The plains generally lie between $+500 \mathrm{~m}$ and $-500 \mathrm{~m}$ of the mean planetary radius (MPR) of $6051.8 \mathrm{~km}$ (fig. 2, on map), with the highest terrain in the region, the northernmost extent of Ishtar Terra (Itzpapalotl Tessera, lat $75^{\circ} \mathrm{N}$., long $\sim 315^{\circ}$ E.), rising more than $6.4 \mathrm{~km}$ above MPR.

Prior to the collection of Magellan radar data, the Soviet Venera 15 and 16 missions offered the only data of the north polar region of Venus (Basilevsky and others, 1986; Barsukov and others, 1986), a region that was not imaged by Earth-based radar studies (Campbell and Burns, 1980; Jurgens and others, 1980; Arvidson and others, 1990; Jurgens and others, 1990; Plaut and Arvidson, 1992) or Pioneer-Venus imagery (Masursky and others, 1980; Pettengill and others, 1980). The data collected during the Venera missions (fig. 3, on map) indicated that the plains of the north polar region were often deformed by sub-parallel linear ridges organized either in ridged belts or in clusters within regional plains, by clusters of small domelike hills, and by impact craters (Barsukov and others, 1985). 
The most prominent ridged belt identified (Dennitsa Dorsa) was described as extending from Atalanta Planitia to the north pole (lat $\sim 160^{\circ} \mathrm{N}$. to $90^{\circ} \mathrm{N}$.) along the long $200^{\circ} \mathrm{E}$. meridian before turning south along the long $80^{\circ} \mathrm{E}$. meridian to abut the eastern edge of the Ishtar Terra highlands as Szél-anya Lineae. The dome-like hills identified ranged in diameter from 1-15 $\mathrm{km}$ and were interpreted to be widely distributed or clustered volcanic domes or cones. Impact craters were observed to have a range in morphologies, including simple bowl-shaped craters, the more common flat-bottomed crater with central peaks and prominent rims, and one multi-ringed crater, Klenova (lat $78.2^{\circ}$ N., long $104.7^{\circ}$ E.). Klenova crater, with a diameter of $140 \mathrm{~km}$, represents one of the largest impact craters identified on Venus (Barsukov and others, 1985). Analyses of data collected during the Venera 15 and 16 missions (Kotelnikov and others, 1989; fig. $3 B$, on map) indicated a surface that was subjected to vast volcanism and a tectonic style unique from terrestrial-style plate tectonics but with exhibitions of horizontal tectonic deformation not seen on the Moon, Mercury, or Mars (Basilevsky and others, 1986).

The Magellan mission returned higher resolution radar and altimetry data that has facilitated a more detailed analysis of the geologic history of Venus (for example, Ford and others, 1989; Arvidson and others, 1991; Phillips and others, 1991; Baker and others, 1992; Campbell and others, 1992; Head and others, 1992; Saunders and others, 1992; Schultz, 1992; Solomon and others, 1992; Tyler and others, 1992; Bindschadler, 1995; Greeley and others, 1995). The north polar region of Venus offers a unique opportunity to observe (1) tectonic interactions between the highest topography in the region, Itzpapalotl Tessera, and the low-lying plains of Snegurochka and Louhi Planitiae to the north, as well as, (2) major volcanic processes that provide insight into the geologic evolution of the planet. Analysis of tectonic interactions between Itzpapalotl Tessera and Snegurochka Planitia conducted from the perspective of Lakshmi Planum (V-7) suggests that the high terrain of Lakshmi Planum formed due to large-scale contraction and underthrusting of plains units from the north beneath the ancient crustal block of Lakshmi Planum to the south (Ivanov and Head, 2009). Further analysis of Snegurochka Planitia (V-1) can further constrain this interpretation.

The spatial and temporal relations between contractional and extensional features such as ridged belts and fracture belts can refine constraints on theories of the timing and nature of the decline of tectonic activity interpreted from the surface geology suggested previously (for example, Herrick, 1994; Kaula and others, 1994; Kaula, 1995; Simons and others, 1997; Head and Basilevsky, 1998; Basilevsky and Head, 1998; Nimmo and McKenzie, 1998; Phillips and Hansen, 1998; Basilevsky and Head, 2000). Similarly, relations between various forms of volcanism observed in this region, including distributed and clustered small shield volcanoes, regional volcanic plains, and isolated large shield and steep-sided volcanoes, can provide insight into the evolution of the crust and mantle of Venus. These issues provide a framework for analysis of our geologic map of Snegurochka Planitia (V-1).

Traditional methods of geologic unit definition and characterization for the planets (for example, Wilhelms, 1990) are modified for the radar dataset available for Venus (for example, Tanaka, 1994; Ivanov and Head, 2001; Basilevsky and Head, 2000; Ivanov and Head, 2009). Geologic units and boundary relations are mapped using mosaics of full-resolution Magellan synthetic aperture radar (SAR) F-MIDR, F-Map, and C1-MIDR data loaded into ArcGIS mapping software at a scale of 1:5 million. Digital versions of Magellan altimetry data are also used to analyze the geology within Snegurochka Planitia (V-1). Venera $15 / 16$ data was not used to supplement the current mapping effort for two reasons: (1) the difference between the resolutions of the two data sets is significant and thus makes mapping on a consistent scale throughout the region impossible, and (2) the region has already been mapped at a larger scale using the Venera 15/16 data (Kotelnikov and others, 1989; fig. 3, on map), and these results yield similar interpretations of regional geologic units and stratigraphy. Several differences can be identified between the two interpretations, however. For example, Szél-anya Lineae was identified as a distinct geologic unit (specifically, a fracture belt, unit $\mathrm{fb}$ ) from the ridged belt (unit rb) of Dennitsa Dorsa using Magellan data whereas it was identified as the same geologic unit (specifically, a ridged belt, unit rb) using Venera data. Also, additional lobate plains units (units pla and plb) and regional plains subunits (units pbs, pds, pbd, and pdd) were identified using Magellan data. These differences in identification can be attributed to the significant increase in resolution of Magellan data relative to Venera data.

\section{Magellan SAR and Related Data}

Mapping was completed using data collected by the synthetic aperture radar (SAR) aboard the Magellan spacecraft. The Magellan SAR instrument operated at a wavelength of $12.6 \mathrm{~cm}$ (S-band) with horizontal and parallel transmit/receive polarization that allowed for cloud penetration and for discrimination of wavelength-scale surface roughness. The data has an effective slant-range resolution of $88 \mathrm{~m}$ and an along-track resolution of $120 \mathrm{~m}$ for each orbital swath of $20 \mathrm{~km} \mathrm{x} \mathrm{17,000} \mathrm{km.} \mathrm{The} \mathrm{major-}$ ity of the SAR images of the north-polar region (lat $75^{\circ}$ N. $-90^{\circ}$ N.) were collected during Cycle 1 of the mission (September 15, $1990-$ September 15,1991$)$ at incidence angles $i$ of $16.5^{\circ}-22.0^{\circ}$, with some overlap occurring at lat $75^{\circ} \mathrm{N}$. in Cycle 2 (through September 15, $1992, \mathrm{i}=24.4^{\circ}$ ), Cycle 3 (through September 14, $\left.1992, \mathrm{i}=27.1^{\circ}\right)$, and Cycle 3 stereo $\left(\mathrm{i}=13.4^{\circ}\right.$, Ford and others, 1993).

The images returned by the Magellan SAR instrument have a maximum resolution of $75 \mathrm{~m} / \mathrm{pixel}$ and reveal variations in surface brightness that reflect surface characteristics including roughness, composition, and slope. Relatively bright surfaces indicate a rougher surface texture whereas relatively dark surfaces represent smoother surface texture at available radar wavelengths, and features oriented perpendicular to the illumination direction appear more prominent than features oriented parallel to the illumination direction. More specific guidelines for geologic mapping using this data and interpreting the data can be found in Saunders and others (1992), Ford and Pettengill (1992), Tyler and others (1992), Ford and others (1993), and Tanaka 
(1994). In addition to radar data, altimetry data, with a footprint of $27 \mathrm{~km}(\mathrm{E}-\mathrm{W})$ by $15 \mathrm{~km}(\mathrm{~N}-\mathrm{S})$ and a vertical resolution of $80-100 \mathrm{~m}$ in the vicinity of lat $80^{\circ} \mathrm{N}$., was used in conjunction with stereo data (left- and right-look C1-MIDR images combined into a single three-dimensional image) to establish spatial and stratigraphic relations between units (Ford and others, 1993). Data sets associated with emissivity (passive thermal radiation), reflectivity (surface electrical properties), and rms slope (distribution of radar wavelength scale slopes) were also used to a lesser extent to aid in interpretations of unit boundaries.

\section{General Geology}

The geologic record of Snegurochka Planitia (V-1) includes features formed from three fundamental geologic processes: tectonism, volcanism, and impact cratering. The tectonic features generally appear bright in the radar backscatter data and can be confined in belts or distributed in asymmetrical patches within surrounding plains. Topography and morphology of these features vary across the region, indicating that several modes of tectonic activity influenced the geology we currently observe on the surface. The features with the highest elevation observed in the region are the northernmost extent of Ishtar Terra, Itzpapalotl Tessera (lat $\sim 75^{\circ}$ N., long $300^{\circ}$ E. $-330^{\circ}$ E.), and the northernmost extent of Fortuna Tessera (lat $\sim 75^{\circ}$ N., long $\sim 10^{\circ}$ E. $-30^{\circ}$ E.). Other identified units of tessera lie near lat $87^{\circ} \mathrm{N}$., long $11^{\circ}$ E. and lat $81.6^{\circ} \mathrm{N}$., long $87.9^{\circ} \mathrm{E}$. These mountain-like regions range in elevation from 1.6 to $6.4 \mathrm{~km}$ above mean planetary radius (MPR $=6051.8 \mathrm{~km}$, fig. 2, on map) and represent some of the most heavily deformed terrains on the planet.

Other tectonically deformed terrains are concentrated into belts $35-200 \mathrm{~km}$ wide and thousands of kilometers long and consist of either contractional or extensional features that are characterized by ranges in elevation from $1.5 \mathrm{~km}$ below MPR to $1.5 \mathrm{~km}$ above MPR. The most prominent deformation belt, Dennitsa Dorsa, is a positive-relief feature in the low-lying plains region that crosses the region at long $\sim 200^{\circ} \mathrm{E}$., extending to lat $90^{\circ} \mathrm{N}$. before turning and continuing as Szél-anya Lineae south along long $\sim 80^{\circ} \mathrm{E}$. (see fig. 1). Dennitsa Dorsa is characterized by clusters of parallel-striking ridges suggestive of a contractional origin (Frank and Head, 1990), whereas Szél-anya Lineae is characterized by clusters of parallel-striking fissures suggestive of an extensional origin. Other ridged belts with similar morphology to Dennitsa Dorsa include Lukelong Dorsa, a negative-relief feature in the intermediately elevated plains near lat $76^{\circ} \mathrm{N}$., long $170^{\circ}$ E., and Fulgora Dorsa, a moderately positive-relief feature near the topographic boundary between the high terrains of Iztpapalotl Tessera and the low plains of Snegurochka Planitia near lat $78^{\circ}$ N., long $340^{\circ}$ E. Other fracture belts with similar morphology to Szél-anya Lineae include Tezan Lineae (lat $\sim 84.8^{\circ}$ N., long $17.5^{\circ}$ E.), a negative-relief feature in low-lying plains, and a positive-relief fracture belt associated with Laka Mons, a large shield volcano near lat $80^{\circ}$ N., long $265^{\circ} \mathrm{E}$.

Other regions of contractional and extensional deformation not confined to belts are scattered throughout the region and are characterized by generally jagged wrinkle ridges and relatively straight grabens, respectively (fig. 4, on map). The plains unit located between latitudes $<75^{\circ} \mathrm{N}$. and $82^{\circ} \mathrm{N}$. and longitudes $82^{\circ} \mathrm{E}$. and $172^{\circ} \mathrm{E}$., for example, contains a high concentration of wrinkle ridges, suggesting these plains underwent significant contraction after emplacement. More recent extensional activity is also indicated in concentrations of grabens cutting plains between latitudes $75^{\circ} \mathrm{N}$. and $77^{\circ} \mathrm{N}$. and longitudes $180^{\circ} \mathrm{E}$. and $190^{\circ}$ E., for example, as well as near the Anahit and Pomona Coronae features (see fig. 1) between latitudes $75^{\circ} \mathrm{N}$. and $81^{\circ}$ N. and longitudes $270^{\circ}$ E. and $330^{\circ} \mathrm{E}$.

Volcanism represents the second fundamental process observed in the geologic record of $\mathrm{V}-1$. Volcanism is expressed in the region through three main classes of features, including regional volcanic plains, large volcanic features (including shield volcanoes and coronae), and small edifices (including steep edifices, steep-sided domes, and small shield volcanoes). Regional plains materials generally are located at low elevations (within $500 \mathrm{~m}$ of MPR) and vary in radar brightness with darker units forming smoother terrain. Similar units investigated elsewhere on Venus are interpreted to be vast fields of potassiumrich mafic lava flows (for example, Surkov and others, 1986; Kargel and others, 1993) that formed either during one catastrophic episode of volcanic activity (Herrick, 1994; Strom and others, 1994; Basilevsky and Head, 1995), during many brief but major episodes of volcanic activity (for example, Phillips and others, 1992), or due to a combination of catastrophic and episodic tectonic events (for example, Solomon, 1993) between 0.3-1.0 Ga (Schaber and others, 1992; Phillips and others, 1992; Solomon, 1993; Herrick, 1994; Strom and others, 1994). The two major plains regions in V-1 include Snegurochka Planitia and Louhi Planitia, and the plains are separated by the major deformation belts Dennitsa Dorsa and Szél-anya Lineae that extend through the region.

The large volcanic features of the region are generally located within the regional plains units and include large shield volcanoes ( $>100$ kilometers in diameter) and coronae. The large shield volcanoes are characterized by significant central topographic highs that rise $0.5-2.0 \mathrm{~km}$ above the surrounding plains and act as sources of lava flows that can extend for more than $250 \mathrm{~km}$ across surrounding units (that is, Renpet Mons, lat $77^{\circ}$ N., long $235^{\circ}$ E.). Laka Mons, a slightly smaller shield volcano located at lat $80^{\circ} \mathrm{N}$., long $\sim 265^{\circ} \mathrm{E}$. with lava flows extending less than $140 \mathrm{~km}$ across surrounding units, appears to be associated with fractured material that may have influenced the emplacement of the volcano. Sarasvati Mons located at lat $75.5^{\circ}$ N., long $\sim 353^{\circ} \mathrm{E}$. has lava flows that extend more than $170 \mathrm{~km}$ across surrounding units and formed near the boundary between the elevated Ishtar Terra terrain and the low-lying Snegurochka Planitia regional plains. The associated asymmetric flows appear to be influenced by local slopes (see fig. 5, on map). These large volcanoes are generally isolated from major tectonic features and appear to be randomly distributed within Snegurochka Planitia.

Similar to the large volcanic features, coronae are characterized by early uplift and volcanism and are thus interpreted to form over sites of mantle upwelling (for example, Pronin and Stofan, 1990; Stofan and Head, 1990; Stofan and others, 1992). However, in contrast to large shield volcanoes, coronae are 
subsequently modified by gravitational relaxation, leading to the formation of a raised, tectonically deformed plateau with a sagging central low surrounded by a trough (for example, Pronin and Stofan, 1990; Janes and others, 1992; Squyres and others, 1992b; Roberts and Head, 1993; Smrekar and Stofan, 1997). Observations of crater frequencies and stratigraphic relations of radial tensile grabens with surrounding units suggest that coronae may have been active within the last $500 \mathrm{Ma}$ (Namiki and Solomon, 1994), though areas used in these analyses might be too small to be statistically significant (Guest and Stofan, 1999). Snegurochka Planitia (V-1) includes three full coronae and one partial corona (Bachue Corona in V-6, Metis Mons; lat $75^{\circ} \mathrm{N}$., long $261^{\circ}$ E.), with Anahit Corona (lat $77^{\circ}$ N., long $280^{\circ}$ E., $400 \mathrm{~km}$ diameter) and Pomona Corona (lat $79^{\circ} \mathrm{N}$., long $300^{\circ}$ E., $350 \mathrm{~km}$ diameter) located completely within the plains of Snegurochka Planitia and Maslenitsa Corona (lat $77^{\circ}$ N., long $205^{\circ}$ E., $200 \mathrm{~km}$ diameter) located on Dennitsa Dorsa, between Snegurochka Planitia and Louhi Planitia. When considered with the large shield volcanoes, there is a noticeable concentration of large-scale volcanic activity within Snegurochka Planitia relative to Louhi Planitia.

Other features associated with volcanic activity observed within V-1 are lava channels. There are two channels observed within dark smooth regional plains material, one located in Snegurochka Planitia (188.3 km long; lat $82^{\circ} \mathrm{N}$., long $266^{\circ} \mathrm{E}$.) and one in Itzpapalotl Tessera $\left(216.8 \mathrm{~km}\right.$ long; lat $76.5^{\circ} \mathrm{N}$., long $338^{\circ}$ E.), and several channels associated with lobate plains materials on the northern flanks of Renpet Mons $(75 \mathrm{~km}, 25.2$ $\mathrm{km}, 30.5 \mathrm{~km}$, and $39.1 \mathrm{~km}$ long; lat $76^{\circ} \mathrm{N}$., long $236^{\circ} \mathrm{E}$.). The channels in the dark smooth regional plains units appear to be sinuous and to cut through the plains units as well as through and around structures that deform the plains units. These observations indicate that the channels formed after the majority of the plains were emplaced rather than at the same time. In contrast, the four smaller channels observed on the flanks of Renpet Mons appear to have transported material downslope, and some have deposits along the margins of the channel. The morphology and location of these channels indicates that the channels formed at the same time as the lobate flows associated with the volcano.

Twenty-three impact craters were identified in the quadrangle (table 1, fig. 6, on map), ranging in diameter from 2.9 $\mathrm{km}$ (unnamed crater: lat $80.9^{\circ} \mathrm{N}$., long $226.4^{\circ}$ E.) to $143.5 \mathrm{~km}$ (Klenova crater: lat $78.2^{\circ} \mathrm{N}$., long $104.7^{\circ} \mathrm{E}$.). The majority of the craters (19) mapped are characterized by a flat floor, and 14 have central peaks. Three of the remaining craters have been deformed by subsequent tectonic activity, and one crater, Klenova, is a large multi-ring basin surrounded by secondary craters. All but six of the craters identified are filled with radar dark material, with the remaining six craters filled with radar bright material; the infilled material may represent volcanic deposits or impact melt and breccia deposits. Some of the smaller craters (Eugenia: $6 \mathrm{~km}$; Tunde: $15.0 \mathrm{~km}$; unnamed cluster: $5.7 \mathrm{~km}, 7.5$ $\mathrm{km}, 5.0 \mathrm{~km}$ ) appear to be part of small clusters of impacts, suggesting that the dense atmosphere of Venus breaks smaller projectiles apart prior to impact (for example, Phillips and others, 1991; Schultz, 1992). A similar phenomenon might explain the formation of a diffuse ring of material surrounding a small central peak southeast of Klenova crater (lat $77.4^{\circ} \mathrm{N}$., long $109^{\circ}$ E.), where the diffuse material might represent windblown material radiating away from a shock wave that originated from an impacting bolide that exploded above the surface.

Snegurochka Planitia (V-1) does not show significant evidence for aeolian activity in wind streaks or deposits piled against topographic highs, suggesting either that surface deposits are resistant to erosion or that surface winds are not significant in this region. One possible exception to this might lie in radar dark plains heavily deformed by wrinkle ridges between latitudes $<75^{\circ} \mathrm{N}$. and $82^{\circ} \mathrm{N}$. and between longitudes $82^{\circ} \mathrm{E}$. and $172^{\circ} \mathrm{E}$. (see fig. $7 A$ ). Many of the ridges in this area have radar bright deposits, generally along one side of the ridge, that may be consistent with redistributed ejecta material or reworked mass-wasted debris (for example, Greeley and others, 1995). However, the radar bright deposits do not consistently lie on the same side of all the ridges, a trend that would be expected in the presence of a prevailing wind direction, and some deposits lie on both sides of the same ridge. While a prevailing wind direction is not required, the disorganized distribution of the radar bright material in this area suggests that aeolian reworking is an unlikely phenomenon, though aeolian reworking may still occur in isolated areas (see fig. $7 B$ ). A possible alternative theory to the formation of these bright deposits is that older radar bright plains were first deformed by wrinkle ridges, generating uneven topography consistent with ridged terrain, and then these radar bright plains were subsequently embayed by younger radar dark lava flows (Ivanov, M., 2008, oral commun.).

\section{Map Units}

The surface of Snegurochka Planitia (V-1) exhibits complex interactions between different materials and structural units. Geologic mapping facilitates the generation and interpretation of a sequence of geologic activity that can provide insight into the history of this region of Venus. Units are generally mapped based on variations in surface roughness or radar brightness; these variations are interpreted to indicate the presence or lack of resolvable deformation that can be associated with observed geologic regions and features. Unit boundaries are distinguished where surface textures observed in the primary surface material change across a visible boundary. There are several areas dominated by structural deformation that masks underlying material properties, and thus these areas are defined according to convention as distinct units because identification of the primary material is no longer possible (for example, Tanaka, 1994; Ivanov and Head, 2009). Spatial distributions of heavily deformed units, regional plains units, and local plains units are shown in figure 8 , and descriptions of regional plains units, local plains units, and structures follow descriptions of the heavily deformed units identified within $\mathrm{V}-1$.

\section{Heavily Deformed Units}

\section{Tessera}

Tessera (units ta, tb, fig. $9 A$ ) are radar bright materials that are generally elevated and are characterized by significant deformation of precursor terrain and high densities of deformation 
structures (for example, Barsukov and others, 1985; Basilevsky and others, 1986; Bindschadler and Head, 1991; Sukhanov, 1992; Solomon and others, 1992; Hansen and Willis, 1998; Hansen and others, 2000; Ivanov and Head, 1996, 2009). Unit ta exhibits a high density of two intersecting orientations of deformation and occupies $290 \times 10^{3} \mathrm{~km}^{2}$ or $4.4 \%$ of the total area of V-1 (table 2), and unit tb, which occupies $17 \times 10^{3} \mathrm{~km}^{2}$ or $0.2 \%$ of the total area, appears to be an elevated and deformed terrain with evidence of significant folding. Although unit tb has a more subdued characteristic deformation pattern, it still displays evidence of extensive deformation in its radar bright, heavily folded texture, leading to its classification as a subunit of tessera.

The tessera material unit ta associated with the northern boundary of Itzpapalotl Tessera (lat $\sim 75^{\circ}$ N., long $300^{\circ}$ E. $-330^{\circ}$ E.) generally has an elevation of $\sim 3 \mathrm{~km}$ above MPR and represents the highest topography in the $\mathrm{V}-1$ region. The other major outcrops of tessera, located near lat $87^{\circ} \mathrm{N}$., long $1^{\circ} \mathrm{E}$. and near lat $81.6^{\circ} \mathrm{N}$., long $87.9^{\circ} \mathrm{E}$., lie in regions that lack topography data, but they appear similar in morphology to the other locations, suggesting that tessera also lie at higher elevations than the surrounding terrain though at significantly lower elevations than Itzpapalotl Tessera. In all cases observed in this region, tessera units are embayed or modified by adjacent material units, as is evident in the discontinuation of deformation lineaments at these boundaries. Multiple theories have been proposed for the origin of tessera terrain (Bindschadler and Head, 1991, and references therein), including deformation driven by asthenospheric flow (Basilevsky, 1986), gravity sliding above either asthenospheric upwellings (Sukhanov, 1986; Smrekar and Phillips, 1988) or mantle upwellings (Pronin, 1986), gravity sliding driven by topographic gradients (Kozak and Schaber, 1986), and convergence of large lithospheric plates or downwelling mantle flow (Bindschadler and Parmentier, 1990). However, the deformation and topography associated with the tessera terrains juxtaposed to Snegurochka Planitia, western Ishtar Terra and Lakshmi Planum, have been interpreted as most consistent with mantle downwelling (Bindschadler and Parmentier, 1990; Bindschadler and others, 1990; Bindschadler and Head, 1991). Specifically, within V-1, observed trends of raised topography and of terrain consistently embayed or deformed by surrounding units are consistent with the idea that tessera formed initially due to substantial contraction and subsequent uplift and crustal thickening early in the geologic history of the region (Phase I, Ivanov and Head, 1996), followed by the formation of secondary deformational lineaments within exposed units, consistent with a later episode of tension (Phase II).

\section{Densely Lineated Plains Material}

Densely lineated plains material (unit pdl, fig. 9B) is radar bright material that is characterized by significant deformation in generally one orientation (for example, McGill, 2000; Rosenberg and McGill, 2001; Campbell and Campbell, 2002; Stofan and Guest, 2003; Basilevsky, 2008; Ivanov and Head, 2009). This deformation is expressed in parallel ridges and grooves that are typically spaced less than $1 \mathrm{~km}$ apart. The mapped unit pdl outcrops in V-1 are generally concentrated in Snegurochka Planitia (fig. 1) with few outcrops in Louhi Planitia, and the unit covers $950 \times 10^{3} \mathrm{~km}^{2}$, or $14 \%$ of the region. Most deposits of unit pdl are small $(<100-200 \mathrm{~km}$ across $)$, though the largest deposits mapped have dimensions of $\sim 100 \mathrm{~km}$ by $\sim 400 \mathrm{~km}$ and are located between latitudes $80^{\circ} \mathrm{N}$. and $82^{\circ} \mathrm{N}$. and between longitudes $230^{\circ} \mathrm{E}$. and $250^{\circ} \mathrm{E}$. These larger unit pdl deposits lie $\sim 200 \mathrm{~m}$ above MPR. Like tessera, the densely lineated plains materials are consistently embayed by surrounding plains units, indicating that they formed during an early stage of intense tectonic deformation.

\section{Ridged Belt Unit}

Ridged belt materials (unit rb, fig. 9C) form radar bright deposits and is characterized by belts of single-orientation deformation ridges. Similar features have been identified in other regions of Venus, and ridged belt properties and theories of origin are discussed at length in the literature (for example, Kryuchkov, 1990; Frank and Head, 1990; Squyres and others, 1992b; Rosenberg and McGill, 2001; Bridges and McGill, 2002). Ridged belts range in width from $\sim 10 \mathrm{~km}$ to $>200 \mathrm{~km}$ and span tens of kilometers to $\sim 2000 \mathrm{~km}$ in length, covering $440 \times 10^{3} \mathrm{~km}^{2}$ or $6.6 \%$ of the $\mathrm{V}-1$ region. The largest ridged belt in the region, Dennitsa Dorsa, $200 \mathrm{~km}$ wide by $\sim 2000$ $\mathrm{km}$ long, forms a topographic boundary that separates the two major regional plains units, Snegurochka Planitia and Louhi Planitia (fig. 1). The topographic signature of Dennitsa Dorsa is complex (fig. 10A), with a trough on each side that dips $\sim 600 \mathrm{~m}$ below MPR and the neighboring plains and a ridge in the center that rises nearly $700 \mathrm{~m}$ above MPR. This trend is not always observed in ridged belts, however (fig. 10B,C); the smaller ridged belts in the region exhibit a negative topography of $\sim 800 \mathrm{~m}$ below the surrounding plains ( $\sim 200 \mathrm{~m}$ below MPR, Lukelong Dorsa, lat $76^{\circ} \mathrm{N}$., long $170^{\circ} \mathrm{E}$.) or a positive topography of $\sim 600 \mathrm{~m}$ above the surrounding plains $(\sim 1.4 \mathrm{~km}$ above MPR, Fulgora Dorsa, lat $78^{\circ}$ N., long $340^{\circ}$ E.). The observation of ridged belts with positive topography and ridged belts with depressed topography may indicate that these features represent a continuum of deformation, from broad arches (Fulgora Dorsa) representing small amounts of shortening, through asymmetric ridge belts (Dennitsa Dorsa) to ridge belts with troughs (Lukelong Dorsa) that may represent underthrusting (Frank and Head, 1990).

Ridged belts appear to have a more complex stratigraphy than the previous two heavily deformed units. Dennitsa Dorsa appears to be consistently embayed by surrounding regional plains at all shared boundaries, as plains units cover deformation structures associated with the ridged belt. Smaller ridges possibly associated with flexure along the margins of the ridged belt may prevent these embaying plains from flooding the lowlying areas of Dennitsa Dorsa. This observation of embayment suggests that Dennitsa Dorsa likely formed early in the geologic history of this region, possibly at a time similar to the formation time of tessera and the majority of the densely lineated plains deposits. Similarly, the boundaries of the main belt of Lukelong Dorsa also appear to be embayed by regional plains units (fig. $10 B)$. However, the high concentration of wrinkle ridges that runs roughly parallel to Lukelong Dorsa in the surrounding regional plains indicates a continued compressive stress regime 
in this area, possibly indicating that the formation of Lukelong Dorsa has been reactivated more recently in the geologic history of this region.

\section{Annulus Unit}

Annulus materials (unit an, fig. 9D) are also radar bright features that are characterized by significant deformation in generally one orientation, but unlike unit pdl, unit an is characterized by broadly concentric deformation patterns. Four outcrops of unit an are observed in $\mathrm{V}-1$, associated with Maslenitsa Corona (lat $76^{\circ}$ N., long $201^{\circ}$ E.), Bachue Corona (in V-6, Metis Mons; lat $75^{\circ}$ N., long $261^{\circ}$ E.), Anahit Corona (lat $77^{\circ}$ N., long $277^{\circ}$ E.), and Pomona Corona (lat $79^{\circ}$ N., long $296^{\circ}$ E.), occupying $100 \times 10^{3} \mathrm{~km}^{2}$, or $1.5 \%$ of the region. Unit an typically lies approximately $0.8 \mathrm{~km}-1.5 \mathrm{~km}$ above MPR and is associated with deformation caused by the formation of coronae. Some instances of tessera also appear to be associated with coronae annuli, particularly with Maslenitsa Corona and Pomona Corona, indicating that the deformation that occurs during corona formation can produce heavily folded terrain (subunit ta) as well as concentrically deformed terrain (unit an). The annuli of the coronae are typically embayed by surrounding regional plains materials, indicating that these features also formed during an early period in the geologic history of $\mathrm{V}-1$.

\section{Fracture Belt Unit}

Fracture belt materials (unit fb, fig. 9E) consist of tectonic features characterized by radar bright terrain and typically parallel fractures confined to a belt of deformed material. Similar features have been identified and discussed previously in the literature as linear ridge terrain (Solomon and others, 1992), as fracture belts (Squyres and others, 1992a; Basilevsky and Head, 2000), and, for some locales identified within V-1, as rift zones (Stofan and others, 1989). In V-1, these belts occupy $200 \times 10^{3}$ $\mathrm{km}^{2}$ or $3.1 \%$ of the total area and range from tens of kilometers to $\sim 100 \mathrm{~km}$ in width and from $\sim 200 \mathrm{~km}$ to more than 1200 $\mathrm{km}$ in length, with the largest fracture belt, Szél-anya Lineae, extending $\sim 1200 \mathrm{~km}$ south along a longitude of $80 \mathrm{o}$ with an average width of $\sim 70 \mathrm{~km}$. The topographic signature of fracture belts varies across the region (fig. 11); portions of Tezan Lineae (fig. $11 \mathrm{~A}$, lat $84.8^{\circ} \mathrm{N}$., long $17.5^{\circ} \mathrm{E}$.) are $\sim 1 \mathrm{~km}$ below the surrounding plains $(\sim 1.6 \mathrm{~km}$ below MPR), portions of Szél-anya Lineae (fig. $11 B$ ) are $\sim 700 \mathrm{~m}$ below neighboring plains $(\sim 1.2$ $\mathrm{km}$ below MPR), and portions of the fracture belt associated with Laka Mons (fig. $11 C$, lat $80^{\circ} \mathrm{N}$., long $259.4^{\circ}$ E.) are $\sim 200$ $\mathrm{m}$ above the surrounding plains ( $\sim 400 \mathrm{~m}$ above MPR). These topographic characteristics might indicate multiple modes of origin for fracture belts as well and thus must be accounted for in hypotheses of origin for fracture belts.

Like ridged belts, fracture belts also have a complex stratigraphy as observed in the north-polar region of Venus. The largest fracture belt in the region, Szél-anya Lineae, appears to be embayed by various plains units at its southern end, but the fractures associated with the northern portion of the belt deform all surrounding units. If the plains in this region were emplaced during a similar time period, the differing interactions with surrounding units suggest that Szél-anya Lineae was active over an extended period of time. The younger, northern portion of Szélanya Lineae interpreted under this assumption is associated with localized, small-scale volcanism that embays local fractures, suggesting that the tensile stresses in the region may have led to volcanism relatively recently in the history of the area. Even if the regional plains units formed at different times, with the more southerly plains deposits representing younger material and the more northerly plains deposits representing older material, leading to the alternative interpretation that the extension associated with the formation of the fracture belt occurred during a single event, the younger, small-scale volcanism observed at the northern extent of the fracture belt suggests that the northern extent of Szél-anya Lineae was active more recently than the southern extent.

\section{Regional Plains Units}

\section{Dark Deformed Plains Material}

Dark deformed plains material (unit pdd, fig. 12A) forms relatively smooth, radar dark deposits that exhibit evidence of subsequent deformation, generally in the form of polygonal cracking or localized, small-scale wrinkles in the terrain. Isolated small mounds interpreted to be shield volcanoes are often observed within unit pdd, and clusters of these shield volcanoes (mapped as unit psh 1 ) can be seen to superpose many of the dark deformed plains materials they border. The dark plains unit likely represents a deformed subunit of the dark smooth plains unit discussed below, but stratigraphic relations between these two units clearly indicate that the latter unit at least partially covers the small-scale cracks or wrinkles associated with the deformed plains units, leading to the distinction of dark deformed plains unit as a separate, generally older unit. As a distinct unit, unit pdd makes up $910 \times 10^{3} \mathrm{~km}^{2}$ or $14 \%$ of the total area of $\mathrm{V}-1$ and appears to be widely distributed throughout $\mathrm{V}-1$, with higher concentrations clustered near the tectonic units described above (fig. 1).

\section{Bright Deformed Plains Material}

Bright deformed plains material (unit pbd, fig. 12B) is generally rougher than unit pdd at a $12.6 \mathrm{~cm}$ wavelength scale, yielding the observed higher radar backscatter. Like the dark deformed plains unit pdd, unit pbd deposits are often characterized by small-scale polygonal cracking or wrinkling of underlying terrain and could represent a deformed subunit of the bright smooth plains unit pbs discussed below. Isolated small shield volcanoes are also found within these deformed plains units, though fewer are observed in unit pbd than in the other plains units. Unit pbd covers $780 \times 10^{3} \mathrm{~km}^{2}$ or $12 \%$ of the total area of $\mathrm{V}-1$ and tends to cluster near the dark deformed plains and the tectonic units described above.

\section{Dark Smooth Plains Material}

Dark smooth plains material (unit pds, fig. 12C) is among the smoothest material in the $\mathrm{V}-1$ region at the $12.6-\mathrm{cm}$ wavelength scale and is distinguished by regions of uniformly low radar backscatter. Some portions of the dark smooth plains unit 
have been deformed by regional tectonic stresses that generated large wrinkle ridges in some locations and grabens in other locations that can be traced across the plains, leading previous examples of these plains to be defined as part of a wrinkle ridge plains unit (unit pwr, Ivanov and Head, 2009), a dark plains unit (Squyres and others, 1992a), a smooth plains unit or a plains with wrinkle ridges unit (unit pwr Basilevsky and Head, 2000), and as the lower unit pwrl of regional plains (Ivanov and Head, 2009). However, because the tectonic deformation does not obscure the original radar dark material, this unit is mapped as a dark smooth plains unit that has been subjected to later tectonic activity. The dark smooth plains are concentrated in Snegurochka Planitia (long $200^{\circ}$ E. $-70^{\circ}$ E.) and Louhi Planitia (long $80^{\circ}$ E. $-190^{\circ}$ E., fig. 1) and make up the most spatially abundant unit in V-1, covering $1.5 \times 10^{6} \mathrm{~km}^{2}$ or $23 \%$ of the total area. Some more localized deposits are observed around Klenova crater (lat $78.2^{\circ} \mathrm{N}$., long $104.7^{\circ}$ E.), and while these deposits may be linked to the formation of Klenova crater (for example, radar-dark parabolas, Campbell and others, 1992; Basilevsky and Head, 2000), they are not observed to be a texturally distinct unit and are thus not mapped as separate units. Isolated shield volcanoes are observed within unit pds, and the greatest concentrations of volcanoes are located near the boundaries of the smooth plains unit where they generally appear to have been covered by dark smooth regional plains deposits.

The dark smooth plains material (unit pds) generally superposes all units described thus far. Deformation lineaments associated with tessera, ridged belt, densely lineated plains, and, on a smaller scale, deformed plains units, tend to be truncated at boundaries shared with the dark smooth plains unit, suggesting that the smooth plains unit (unit pbs) was emplaced after units ta, tb, pdl, pdb, and pbd. Some lineaments associated with fracture belts also are truncated by the dark smooth plains unit, specifically the southern extent of Szél-anya Lineae, though other fracture belt lineaments, such as in the northern extent of Szélanya Lineae, cut through nearby deposits of the dark smooth plains unit. This observation, in conjunction with observations of other deformation structures (specifically, wrinkle ridges and lineaments) within dark smooth plains deposits, indicates that this region of Venus has continued to be tectonically active after the emplacement of the dark smooth plains unit.

\section{Bright Smooth Plains Material}

Bright smooth plains material (unit pbs, fig. 12D) has a higher radar backscatter suggesting that it has a greater surface roughness than the dark smooth plains unit. Similar plains have been identified previously as part of the upper unit of regional plains with wrinkle ridges (unit pwr2 in Basilevsky and Head, 2000), but the current characterization describes the original unit and interprets superposed features such as wrinkle ridges as subsequent tectonic deformation. Bright smooth plains deposits cover $480 \times 10^{3} \mathrm{~km}^{2}$ or $7.2 \%$ of the total area, and they are typically located near boundaries between deformed units and stratigraphically younger regional plains units and have outer boundaries that are generally characterized by lobate geometries (for example, fig. 12D, at the boundary between Fortuna Tessera and Snegurochka Planitia, lat $78^{\circ}$ N., long $10^{\circ}$ E.). Observations generally indicate that the bright smooth plains unit superposes surrounding materials including the dark smooth plains unit, indicating that bright smooth plains deposits comprise the youngest regional plains unit observed in the region.

\section{Local Plains Units}

\section{Shield Plains Units}

Shield plains (units $\mathrm{psh}_{1}, \mathrm{psh}_{2}$, fig. 13A) are characterized by clusters of small shield-like mounds (1-20 km in diameter) that generally have a radar bright center surrounded by a more subdued radar bright apron. Each mound is mapped as an individual structure (see fig. $4 C$, on map), and shield plains are mapped as a unit when the aprons, interpreted to be volcanic flows associated with the mounds, overlap or lie in close proximity to other aprons (in other words, when they cluster), forming a somewhat radar-mottled appearance. Mounds may be randomly distributed in a cluster (fig. 14A, on map) or they may be aligned along a fracture (fig. 14B, on map). Similar features have been identified previously and are mapped as distinct units in many other areas on Venus (for example, Basilevsky and Head, 1988, 1995; Crumpler and Aubele, 2000; Ivanov and Head, 2001, 2009). Outcrops of shield plains units cover 270 $\mathrm{x} 10^{3} \mathrm{~km}^{2}$, or $4.1 \%$ of the total area within $\mathrm{V}-1$ at generally intermediate elevations between deformed materials such as the densely lineated plains unit ( $\mathrm{pdl}$ ), ridged belt unit ( $\mathrm{rb})$, and fracture belt unit ( $\mathrm{fb}$ ) and plains materials such as radar dark and bright deformed units and the radar dark smooth plains unit (pbd, pdd, pbs, pds; fig. 14A, $B$, on map). The aprons, or flows, appear to cover the more deformed materials such as units $t$ and $\mathrm{rb}$ and the deformed plains materials such as unit pdl, but the aprons appear to be covered by the smoother regional plains units pds and pbs in most cases. This indicates that, in general, the lower shield plains unit ( $\left.p h_{1}\right)$ formed between episodes of deformed regional plains unit emplacement and episodes of smooth regional plains emplacement. Shield plains unit $\mathrm{psh}_{1}$ covers $264.6 \times 10^{3} \mathrm{~km}^{2}$ or $4.0 \%$ of the total area. Two exceptions to this trend in the stratigraphy of shield plains have been identified within the region, with one cluster partially covering the central caldera of the large shield volcano Renpet Mons (fig. $14 C$, lat $77^{\circ} \mathrm{N}$., long $235^{\circ}$ E., on map) and with the second covering the young fractures observed at the center of the northern extent of the fracture belt Szél-anya Lineae (see fig. $21 B$, on map). These two exceptions (unit psh2) indicate that locally, conditions required to produce small shield volcanism existed relatively recently in the history of this region. This upper shield plains unit covers $2.9 \times 10^{3} \mathrm{~km}^{2}$ or $0.04 \%$ of the total area.

\section{Bright Deformed Corona Plains Material}

Bright deformed corona plains material (unit pcbd, fig. $13 B$, white arrow) is similar in texture and appearance to bright deformed regional plains, with a generally high backscatter and small-scale polygonal cracking or wrinkling of underlying terrain observed. Similar units have been identified in other regions of Venus and have been mapped, for example, as "corona material a" unit coa (V-5, Rosenberg and McGill, 2001). Deposits of this local bright deformed plains unit in 
V-1 are observed to be spatially associated with the exterior of coronae in the region and cover $56 \times 10^{3} \mathrm{~km}^{2}$ or $0.85 \%$ of the total area of $\mathrm{V}-1$. These deposits are typically younger than annulus unit an and tessera unit ta materials, at least partially covering deformation associated with these units. In contrast, these deformed coronae plains are generally embayed by smooth regional plains materials (units pds, pbs), as the smallscale wrinkles associated with these locally deformed plains are truncated at boundaries with these smoother regional plains materials.

\section{Dark Smooth Corona Plains Material}

Dark smooth corona plains material (unit pcds, fig. 13C) is similar in texture and appearance to the dark smooth regional plains unit, with uniformly low radar backscatter at the $12.6-\mathrm{cm}$ wavelength scale. Deposits of this local dark smooth plains unit are observed to be spatially associated with the interior of coronae in the region and occupy $41 \times 10^{3} \mathrm{~km}^{2}$ or $0.60 \%$ of the total area of $\mathrm{V}-1$. The dark smooth plains unit generally superposes most of the adjacent units, including annulus unit an, densely lineated plains unit pdl, and shield plains unit psh 1 . Deformation lineaments associated with annulus and densely lineated plains units tend to be truncated at boundaries shared with the dark smooth plains unit, suggesting that the smooth plains unit was emplaced after these other units. Similar units have been identified in other regions of Venus and have been mapped, for example, as "corona material b" unit cob (V-5, Rosenberg and McGill, 2001).

\section{Bright Smooth Corona Plains Material}

Bright smooth corona plains material (unit pcbs, fig. $13 B$, black arrow) is similar in texture and appearance to the bright smooth regional plains unit, with a higher radar backscatter at the 12.6-cm wavelength scale. Similar plains material has been identified in other regions of Venus and have been mapped, for example, as "corona material c" unit coc (V-5, Rosenberg and McGill, 2001). These deposits are generally observed in association with the exterior of coronae in $\mathrm{V}-1$, though at least one deposit of unit pcbs flows into the interior of Pomona Corona. These deposits cover $190 \times 10^{3} \mathrm{~km}^{2}$ or $2.8 \%$ of the total area in $\mathrm{V}-1$, and observations generally indicate that bright smooth plains superpose all surrounding materials including annulus unit an materials, densely lineated plains unit pdl, shield plains unit psh 1 , dark smooth regional plains unit pds, and dark smooth corona plains unit pcds, indicating that these deposits comprise the youngest subunit observed in the region.

\section{Lobate Plains Units}

Lobate plains units (pla and plb, fig. $13 D, E$ ) have a distinctive radial or lateral texture and a radar bright, digitate morphology at the outer extents of the deposits. These deposits are almost uniformly undeformed by wrinkle ridges and extensional lineaments and are similarly identified in previous mapping efforts as a digitate plains unit (Squyres and others, 1992a) and a lobate plains unit (Head and others, 1992). These lobate deposits nearly uniformly cover or surround all adjacent units, indicating that the lobate plains unit is among the youngest units observed in the region. Margins of lobate deposits occur within the boundaries of the mapped units, indicating sequential episodes of emplacement. These internal margins have been designated as flow fronts but not unit boundaries, as the deposits in the unit extend beyond the internal flow fronts. There are four occurrences of the lobate plains unit within $\mathrm{V}-1$, with three locations characterized by material distributed radially around a centrally elevated region (covering a total area of $240 \times 10^{3}$ $\mathrm{km}^{2}$ or $3.6 \%$ of the region), apparently originating from a point source (unit pla), and one location characterized by material distributed linearly across surrounding plains (covering a total area of $21 \times 10^{3} \mathrm{~km}^{2}$ or $0.3 \%$ of the region), apparently originating from tensile structural features that deform surrounding regional plains materials (unit plb). The radial lobate plains deposits tend to be associated with a centralized topographically elevated region, including plains associated with Renpet Mons (fig. $13 D$, lat $77^{\circ} \mathrm{N}$., long $235^{\circ}$ E.), Laka Mons (lat $80^{\circ} \mathrm{N}$., long $265^{\circ}$ E.), and Sarasvati Mons (lat $75.5^{\circ}$ N., long $353^{\circ}$ E.). The distribution of the deposits associated with Renpet Mons and Laka Mons appear to be nearly radially symmetric, extending $>250 \mathrm{~km}$ and $<140 \mathrm{~km}$ from the central region, respectively. In contrast, the deposits associated with Sarasvati Mons and Heloha Fluctus are not radially symmetric, extending almost $500 \mathrm{~km}$ to the northwest but only $\sim 100 \mathrm{~km}$ to the southeast and northeast and not at all to the southwest. These trends are dependent on the topography in the area (see fig. 5, on map). The regional plains in the vicinity of Renpet Mons and Laka Mons lie at a generally constant elevation of $\sim 500 \mathrm{~m}$ and $\sim 200$ $\mathrm{m}$ above MPR (6051.8 km), respectively, while the regional plains in the vicinity of Sarasvati Mons are confined to a trough along the base of a cliff associated with the boundary between Iztpapalotl Tessera and Snegurochka Planitia, and these deposits follow a regional downward slope of $\sim 0.1 \%$ to the northeast. These topographic trends are consistent with the observed distributions of the lobate plains units. In contrast to these pointsource lobate plains unit materials, the linear lobate plains unit materials observed in $\mathrm{V}-1$ (fig. $13 \mathrm{E}$, lat $78^{\circ} \mathrm{N}$., long $286^{\circ} \mathrm{E}$.) appear to be associated with the outer extent of tensile structural features that extend from Pomona Corona (lat $79^{\circ} \mathrm{N}$., long $300^{\circ}$ E.), suggesting that these deposits were emplaced by surface eruptions from laterally propagating dikes. These deposits of lobate plains (unit plb) superpose all surrounding units, indicating that activity related to the development of Pomona Corona is younger than activity associated with the development of Anahit Corona and with local emplacement of the regional plains units.

\section{Edifice Material}

Edifice material (unit ed, fig. 13F) consists of distinct features characterized by radar bright lines emanating from a central high and by radial radar bright, hummocky material at larger distances of up to $30-50 \mathrm{~km}$ from the feature centers. The distinct radar bright lines have been identified previously as an effect of radar data of steep slopes, termed layover, in which the top of a feature is imaged before the bottom of the near-range slope (Ford and others, 1989; Farr, 1993). The 
hummocky deposits located on the flanks of the edifice are related to flank failure processes, where material deposited on the steep edifice slopes collapses and is deposited on the surrounding plains materials (Bulmer and Guest, 1996). The presence of this effect indicates that these edifices have much steeper slopes than typical volcanoes observed on Venus. Three edifices were identified on the flanks of Renpet Mons within $\mathrm{V}-1$, including Eirene (lat $75.5^{\circ} \mathrm{N}$., long $230^{\circ}$ E.), Yansa (lat $76.1^{\circ} \mathrm{N}$., long $232.2^{\circ}$ E.), and Akka (lat $75.1^{\circ} \mathrm{N}$., long $233^{\circ}$ E.) Tholi, covering a total of $7.6 \times 10^{3} \mathrm{~km}^{2}$, or $0.11 \%$ of the total area. While their spatial extent is limited, edifices have a distinct placement in the stratigraphy of the region, apparently forming contemporaneously with Renpet Mons as deposits associated with the edifices both lie above Renpet Mons flows and deflect subsequent flows.

\section{Craters}

\section{Undifferentiated Crater Material}

Undifferentiated crater material (unit c, see fig. 6, on map, table 1) is a unit generally characterized by radar bright material at least partially surrounding a deformed ring that encloses a generally radar dark circle and in many cases a central radar bright peak. Dark material identified around craters in other regions of Venus (for example, Campbell and others, 1992; Ivanov and others, 1992; Schultz, 1992; Basilevsky and Head, 2000; Ivanov and Head, 2009) may surround Klenova crater (lat $78.2^{\circ} \mathrm{N}$., long $104.7^{\circ} \mathrm{E}$.) but is generally not observed or mapped in V-1. Details of the morphologies of the twenty-three craters identified in $\mathrm{V}-1$ are summarized in table 1 and are described in more detail in the General Geology section. Undifferentiated crater material occupies $120 \times 10^{3} \mathrm{~km}^{2}$, or $1.7 \%$ of the total area within $\mathrm{V}-1$.

\section{Structures}

\section{Wrinkle Ridges}

Wrinkle ridges (fig. 15A) are generally characterized by sharp ridges with sharp radar bright peaks that deform underlying terrain and range in length from $0.7 \mathrm{~km}$ to $320 \mathrm{~km}$ (from over 6800 wrinkle ridges mapped). Lengths were measured by applying the ArcGIS length calculator to each mapped wrinkle ridge, and they represent the complete length of each observed wrinkle ridge. Ridges are distinguished from wrinkle ridges in that ridges have broader crests rather than sharp peaks, and ridges are generally found in isolation, embayed by surrounding regional plains units, or in small ridged belts.

There are four main clusters of wrinkle ridges in $\mathrm{V}-1$ (see fig. 4, on map): (1) in the dark smooth regional plains surrounding Klenova crater (lat $78.2^{\circ} \mathrm{N}$., long $104.7^{\circ}$ E.), (2) near Lukelong Dorsa (lat $76^{\circ}$ N., long $170^{\circ}$ E.), (3) on Snegurochka Planitia just north of its boundary with Fortuna Tessera (near lat $79^{\circ} \mathrm{N}$., long $11^{\circ} \mathrm{E}$.), and (4) in the regional plains deposits surrounding Anahit Corona (lat $77^{\circ}$ N., long $280^{\circ}$ E.). Upon further investigation of Venera 15/16 data in the Magellan data gap (long $115^{\circ}$ E. $-156^{\circ}$ E., see fig. 3, on map), the first two sets of wrinkle ridges listed appear to be related to each other and possibly also to the northernmost extent of Lukelong Dorsa (latitudes $76^{\circ} \mathrm{N}$. to $77.6^{\circ} \mathrm{N}$., longitudes $156^{\circ} \mathrm{E}$. to $171^{\circ} \mathrm{E}$., continued to the south in $\mathrm{V}-5$, Rosenberg and McGill, 2001) nearly due east across the dark smooth regional plains. The wrinkle ridges near the topographic boundary between Fortuna Tessera and Snegurochka Planitia appear to extend perpendicular to the $\sim 2.5 \mathrm{~km}$ change in elevation, extending to the north and northwest, deforming only the surrounding regional plains units. The final set of wrinkle ridges identified appears to radiate to the east, northeast, and southwest of Anahit Corona, though they are partially embayed by predominantly dark smooth regional plains material to the east of the feature. There are also a significant number of wrinkle ridges associated with ridged belts, but because these features are contained within the tectonic unit $\mathrm{rb}$, they are not mapped as distinct features. Wrinkle ridges in general indicate regions of localized compression, and clusters of these structures can thus be used to identify temporal and spatial episodes of compression within $\mathrm{V}-1$. The distribution of these features within $\mathrm{V}-1$ is consistent with global observations, with the highest density of wrinkle ridges concentrated in topographically low regional plains units (Bilotti and Suppe, 1999). Also, there is not a ring of compressive deformation observed along the north boundary of the high elevation regions of Ishtar Terra and Itzpapalotl Tessera, consistent with the idea that not all major topographic swells formed at the time of wrinkle ridge formation (Bilotti and Suppe, 1999).

\section{Simple Ridges}

Simple ridges (fig. 15B) are characterized by more prominent, rounded ridge crests. Simple ridges can be clustered, often with smaller scale wrinkle ridges, to form distinct geologic units such as the ridged belts unit $\mathrm{rb}$. The ridges mapped in the $\mathrm{V}-1$ region range in length from $2 \mathrm{~km}$ to $235 \mathrm{~km}$ (from over 400 mapped ridges) and are typically associated with geologic units rb, pdl, and an. Ridges appear to be clustered predominantly along the northern and eastern boundaries of the regional plains units that form Snegurochka Planitia, in the ridged belt units associated with Dennitsa Dorsa, with the annuli units associated with the coronae, and with the densely lineated plains unit associated with the northern boundaries of Itzpapalotl Tessera (see figs. $1 B$ and $4 B$ ).

\section{Lineament Structures}

Lineament structures (fig. 15B) are characterized by long, linear fractures or fracture segments that cut underlying terrain and range in length from $0.4 \mathrm{~km}$ to $165.2 \mathrm{~km}$ (from nearly 11,000 fractures mapped). Again, lengths are measured by applying the ArcGIS length calculator to each mapped lineament. Fractures can appear as single straight lines or as double lines with a radar shadow juxtaposed to a radar bright wall, indicating the presence of a trough or graben (for example, Head and others, 1991; Solomon and others, 1992; Grosfils and Head, 1994; Ernst and others, 2001, 2003). The radar shadow lies on the side of the trough that is hidden from incoming radar and thus points in the direction from which the incident waves arrive. 
The three most prominent clusters of lineaments are located near long $80^{\circ} \mathrm{E}$. from lat $75^{\circ} \mathrm{N}$. to $85^{\circ} \mathrm{N}$. and from long $285^{\circ}$ E. to $320^{\circ} \mathrm{E}$., where lineaments radiate from two central points near lat $77^{\circ} \mathrm{N}$., long $280^{\circ} \mathrm{E}$. and lat $79^{\circ} \mathrm{N}$., long $300^{\circ} \mathrm{E}$. (see fig. 4, on map). The first cluster is closely associated with the fracture belt Szél-anya Lineae, and the concentration of fractures near lat $84^{\circ} \mathrm{N}$., long $95^{\circ}$ E. represents the interaction of the northern extent of this fracture belt with the surrounding plains as the fractures deform underlying material. The second cluster of lineaments is associated with Anahit Corona, with the most prominent fractures lying to the northwest of the feature, and the third, much denser cluster of fractures is associated with the nearby Pomona Corona, with fractures lying in every direction except to the southeast, where the prominent Itzpapalotl Tessera, where thicker crust likely inhibits the formation of these features. The fractures that lie to the west of Pomona Corona are covered by radar bright and lobate plains at their outer extents, and the presence of these plains units indicate that the fractures at this location are likely to be dikes that radiate from Pomona Corona. A fourth, more minor cluster of lineaments that is also interpreted to be dikes is located near lat $76.7^{\circ} \mathrm{N}$., long $181^{\circ} \mathrm{E}$., where mounds interpreted to be small shield volcanoes form in line with fractures that extend into the shield plains unit $\left(\mathrm{psh}_{1}\right)$ from the neighboring densely lineated plains unit (pdl). We interpret that these fissures, identified to be dikes, fed the eruptions that formed the small shield volcanoes observed.

\section{Central Peaks}

Central peaks (see fig. 6 (on map) and table 1, craters $9,15,19$, for example) are typically characterized by a steep dome-like structure observed near the center of an impact crater. Of the 23 impact craters observed within the $\mathrm{V}-1$ region, 15 have mapped central peaks; the smallest crater with an identified central peak is Janice (fig. 6 (on map), crater 5, lat $87.3^{\circ} \mathrm{N}$., long $261.9^{\circ} \mathrm{E}$., diameter $\left.11.9 \mathrm{~km}\right)$, and the largest crater with a mostly embayed cluster of central peaks is Lagerlof (fig. 6 (on map), crater 22 , lat $81.2^{\circ} \mathrm{N}$., long $285.1^{\circ} \mathrm{E}$., diameter $59.8 \mathrm{~km}$ ).

\section{Steep-sided Domes}

Steep-sided domes (fig. 15C) are domes characterized by steep edges bounding broad, flat plateaus. Eight steep-sided domes have been identified in the $\mathrm{V}-1$ area, all clustered near the northern extent of Szél-anya Lineae (lat $84.6^{\circ} \mathrm{N}$., long $88.4^{\circ}$ E.). These domes may represent eruptions of highly viscous material (Pavri and others, 1992) and are informally referred to as "pancake domes" in the literature (for example, Bridges, 1995; Stofan and others, 2000). These steep-sided domes are observed in deformed regional plains units pdd and pbd that are significantly cut by lineaments, and these lineaments alternatively cut and are covered by the steep-sided domes, suggesting a concurrent formation for the lineaments and dome structures.

\section{Stratigraphic Relations of Units}

The identification and separation of Snegurochka Planitia $(\mathrm{V}-1)$ into different units and structures facilitate further analysis as to the timing and evolution of geologic activity in this north polar region of Venus. The geologic history of this region can be constructed by focusing on stratigraphic relations between neighboring units, with specific emphasis placed on superposition and crosscutting relations between material and structural units (see Correlation of Map Units). Unfortunately, absolute ages cannot be assigned to these stratigraphically mapped material units because of a nearly random spatial distribution of impact craters across the surface of Venus (for example, Phillips and others, 1992; Campbell, 1999), though some suggested localized crater concentrations may support several episodes of regional plains emplacement (for example, Hauck and others, 1998).

The oldest unit that has consistently been identified in V-1 as well as the rest of the surface of Venus is tessera, a unit that is interpreted to be somewhat analogous to terrestrial mountainous terrain with thickened crust (for example, Bindschadler and Head, 1991; Ivanov and Head, 1996; Head and Basilevsky, 1998; Basilevsky and Head, 2000; Hansen and others, 2000).

Direct interactions between tessera outcrops and units such as dark deformed, dark smooth, and bright smooth regional plains, shield plains, and fracture belts indicate that these latter units formed after the tessera unit, with plains units covering and fractures deforming the heavily deformed tessera unit (for example, fig. $16 A$, on map). Grabens that subsequently deform the tessera unit are observed in portions of tessera units within $\mathrm{V}-1$, though the more narrow and longer troughs and ridges associated with ribbon terrain that is identified elsewhere on the planet (for example, Phillips and Hansen, 1998; Hansen and Willis, 1998; Hansen and others, 2000) is not observed in $\mathrm{V}-1$. These features indicate that tensile stresses resulted in the deformation of tessera materials after the initial compressive stresses responsible for the formation of these units ceased. Other lineaments associated with the densely lineated plains unit in Itzpapalotl Tessera appear to have been deformed by tessera-associated deformation, possibly indicating a concurrent formation (fig. 16B, on map).

The densely lineated plains unit is interpreted to have formed next in the sequence observed in $\mathrm{V}-1$. These older plains materials are interpreted to be modified by either localized tensile or compressive stresses, depending on whether fractures or ridges make up the deformation of the unit, though the majority of the densely lineated plains unit appears to have formed as the result of compressive stresses. Outcrops of the densely lineated plains unit are generally modified by younger fractures and embayed by the shield plains, smooth regional plains, and lobate plains units, relations that are interpreted from observations of fractures cutting across the deformed unit pdl and by the smoother units psh 1 , pds, pbs, pla, and plb that cover lineaments associated with unit pdl (for example, fig. 17, on map). In some isolated locations such as lat $76.8^{\circ}$ N., long $180^{\circ}$ E. (see fig. $14 B$, on map), the shield plains unit appears to form concurrently with the densely lineated plains unit, as mounds interpreted to be shield volcanoes form in line with fractures that extend from the deformed plains unit into the shield plains unit. This relation suggests that these fractures may be expressions of subsurface dikes that breached the surface to feed localized eruptions and the formation of these shield volca- 
noes (for example, Head and others, 1996; Jonsson and others, 1999; Wilson, 2001).

Annulus unit an is also interpreted to form during an early geologic period associated with the three coronae features located within V-1 (for example, see fig. 9C). Coronae are interpreted to form as a thermal plume ascends, uplifting the crust and inducing surface volcanism before collapsing, resulting in gravitational relaxation of the crust (for example, Pronin and Stofan, 1990; Janes and others, 1992; Squyres and others, 1992b; Roberts and Head, 1993; Smrekar and Stofan, 1997). As the crust is uplifted, the terrain that is pushed outward forms concentric ridges that are mapped as the corona annulus as well as outcrops of isolated tessera unit ta (lat $79.9^{\circ} \mathrm{N}$., long $292^{\circ}$ E.). In the case of Maslenitsa Corona (lat $76.8^{\circ} \mathrm{N}$., long $202.3^{\circ}$ E.), the associated annulus unit an and surrounding plains units pcbd and pcbs lie adjacent to the ridged belt Dennitsa Dorsa. While the unit rb associated with Dennitsa Dorsa appears to be embayed by the northernmost corona plains unit pcbs associated with Maslenitsa Corona, the unit rb appears to curve around the westernmost unit an of the corona. These observations support the theory of extended corona evolution, as the annulus unit of Maslenitsa Corona may have formed either before or concurrently with Dennitsa Dorsa, forming a topographic barrier that diverted the formation of the ridged belt unit, and subsequent emplacement of the corona plains units covered the older ridged belt. These relations indicate that volcanism and extension occurred in multiple episodes over extended periods of time to form the feature observed today.

This trend of extended corona formation is also evident in Pomona Corona. Localized volcanism occurred early in the evolution of the corona outside the annulus, with the emplacement of both regional plains units (pdd, pbd) and the local plains unit pcbd. These plains units were subsequently deformed by the formation of grabens radiating away from the corona annulus (lat $80.4^{\circ} \mathrm{N}$., long $303.4^{\circ} \mathrm{E}$.) or by the formation of wrinkle ridges associated with the continued formation of the corona annulus (lat $77.4^{\circ}$ N., long $280.5^{\circ}$ E.). Subsequent emplacement of regional plains units as well as more local plains units surround (pbd, pdd, pbs, pds, pcbs) and fill (unit pcds) the central plateau of the coronae. Materials associated with unit pcbs associated with Pomona Corona, for example, both cover older fractures and are cut by younger fractures that radiate from the nearby corona (fig. 18, on map). In the case of Pomona Corona, these fractures appear to be the source of the nearby volcanic unit plb (see fig. 13C). The volcanic flows postdate features associated with the neighboring Anahit Corona, indicating that Pomona Corona was active more recently than Anahit Corona in this area. Additionally, materials associated with the younger local plains units pcbs and pcds are observed in association with each corona observed in $\mathrm{V}-1$, with radar bright material (unit pcbs) typically covering other regional plains units as well as structures that radiate from the coronae, and with radar dark material (unit pcds) covering the interior of the corona plateaus. Contacts between units pcbs and pcds are rare, but where the two units interact in the plateau of Pomona Corona (lat $78.6^{\circ}$ N., long $299^{\circ}$ E.), unit pcbs appears to embay unit pcds. These embayment relations support the theory that volcanic activity is consistent with late-stage coronae evolution, with the formation of units pcbs and plb representing the youngest activity associated with coronae.

Structures within ridged belts appear to deform densely lineated plains when these units interact, indicating in general a more recent formation age for the ridged belt unit. The ridged belt unit is then typically embayed by regional plains units pds and pbs and shield plains unit psh 1 (for example, fig. $19 A$, on map). Prior to analysis of Magellan data, ridged belts were interpreted to form due to either regional extension (for example, Sukhanov and Schubert, 1989) or regional contraction (for example, Frank and Head, 1990; Kryuchkov, 1990, and references therein). Observations of the Magellan data in Snegurochka Planitia (V-1) support a contractional origin, as the ridged belts appear to be clusters of ridges that have been compressed into a belt of deformed material. Topographic observations of troughs at the edge of the raised belts of Dennitsa Dorsa and Lukelong Dorsa indicate that contraction and even possible underthrusting may occur during the formation of these ridged belts (fig. 10; fig. 18 (on map) in Frank and Head, 1990). Wrinkle ridges parallel to Lukelong Dorsa and fractures perpendicular to the wrinkle ridges appear to be associated with the formation of ridged belts such as Lukelong Dorsa (fig. 19B, on map), with wrinkle ridges trending perpendicular to the most compressive stress and fractures propagating parallel to the most compressive stress. While similar features near Dennitsa Dorsa have possibly been covered by regional plains material, the presence of these younger structural lineaments in the vicinity of Lukelong Dorsa might indicate that subsequent regional volcanic activity has not yet concealed these tectonic imprints, suggesting that several episodes of ridged belt formation might be evident in this part of the north polar region of Venus.

These early episodes of intense tectonic activity responsible for the deformation of precursor material into tessera, densely lineated plains, annuli, and at least some ridged belts, were followed by several episodes of volcanic plains emplacement. Multiple episodes of plains emplacement are evident in the complex stratigraphic relations between the four identified regional plains units, though absolute time differences cannot be distinguished based on these observations. The first episode of regional plains emplacement resulted in the deposition of extensive lava flows currently observed and mapped as dark and bright deformed regional plains units pdd and pbd. These material units are defined by small-scale deformation features such as polygonal cracks that generally are truncated at boundaries shared with other smoother plains units. These stratigraphically younger, smoother regional plains units pds and pbs are interpreted to be associated with a second episode of regional plains emplacement that occurred later, forming the dark smooth plains unit that covers most of the north polar region of Venus (fig. 20A, on map). Source vents for these regional plains have not yet been identified, and they may be covered by the plains themselves or the vents may be below the resolution of the data $(75 \mathrm{~m} /$ pix $)$. The most recent observed episode of regional plains emplacement resulted in the deposition of the bright smooth regional unit pbs. Generally, these youngest plains are observed to superpose surrounding plains units pdd, pbd, and pds close to topographic boundaries such as the boundaries between Fortuna Tessera and Snegurochka Planitia and the areas surrounding Tezan Lineae 
(lat $84.7^{\circ}$ N., long $19.4^{\circ}$ E.). Some unit pbs materials may have originated from more local point sources along these topographic boundaries (fig. 20B, on map), indicating possible late-stage volcanism associated with these features, but their consistently bright morphology and their lack of a clear central source leads to their classification as a regional plains unit.

While observations of these plains unit boundaries indicate that several episodes of emplacement are required to yield the stratigraphy seen between the different regional plains units, these observations cannot be used to assign an absolute time elapsed between episodes. In fact, little or no time might have elapsed between emplacement events; the stratigraphy may indicate different magma or vent sources rather than different times. However, the overall trend of emplacement and subsequent modification of the older deformed plains units pdd and pbd followed by emplacement of the younger radar dark plains unit pds, then the emplacement of radar bright smooth plains unit pbs, is observed throughout the region and is thus incorporated into the stratigraphic column.

The lower shield plains unit psh 1 was observed to form mostly between episodes of emplacement of the deformed and smooth regional plains units, with evidence of interactions with units of various ages preserved in the $\mathrm{V}-1$ region. These relations were interpreted based on criteria for the stratigraphy of the shield plains unit presented by Ivanov and Head (2004a). Their stratigraphy with older units is preserved locally, with individual shields or shield plains forming on or adjacent to previously emplaced tessera, ridged belt, and densely lineated plains units (see fig. 17, on map), as well as deformed regional plains units (for example, fig. 21 $A$, on map). Lower shield plains materials (unit $\mathrm{psh}_{1}$ ) tend to be preserved at intermediate elevations where they generally have been embayed by younger, lower lying regional plains units. In some cases, regional plains units conceal the radar bright aprons associated with the small shields, leaving behind a cluster of peaks that appear to increase in size as the embaying plains units decrease in thickness with increasing topography (for example, Head and others, 1992; Kreslavsky and Head, 1999; Ivanov and Head, 2004a). The majority of the lower shield plains materials (unit psh 1 ) observed in V-1 follow this trend, suggesting that the most active time of lower shield plains unit formation occurred after the emplacement and subsequent modification of the deformed regional plains units but before the emplacement of the smooth regional plains units pds and pbs (for example, figs. 14B, 22A, on map). In contrast, observations of upper shield plains unit $p_{2} h_{2}$ materials cover some of the youngest units in the region, including the fracture belt unit associated with Szél-anya Lineae (fig. 21B, on map) and the lobate plains unit associated with Renpet Mons (see fig. 14C, on map), indicating that younger episodes of shield plains formation has occurred. The observations of the two instances of shield plains, (1) unit psh 1 deposits that are partially embayed by younger smooth plains materials at intermediate elevations and (2) unit psh $\mathrm{p}_{2}$ deposits that embay relatively young features such as lobate flows and fracture belts that embay and deform surrounding deposits, respectively, indicate that shield plains formed in at least two stratigraphically distinct episodes in the geologic history of this region.
The youngest units mapped in the north polar region of Venus include some fracture belts (unit fb), lobate plains (unit $\mathrm{pl}$ ), edifices (unit ed), and local smooth radar dark and bright plains units associated with late-stage coronae development (units pcds, pcbs). Fracture belts such as Szél-anya Lineae appear to have formed over extended periods of time, with some areas showing evidence of embayment of regional plains units (fig. 22A, on map) while others clearly cut through the surrounding plains unit material (see fig. $21 B$, on map). The outcrops of the fracture belt unit that have been embayed appear to be tectonically stable, as subsequent fracturing associated with the fracture belt unit has not continued after the emplacement of surrounding material. In contrast, the areas that appear younger than the surrounding plains units appear to have been active more recently than surrounding units, with associated fracturing and local volcanism cutting and covering all adjacent materials. A local concentration of volcanism occurs in the form of a cluster of small shield volcanoes near the center of the more recently active northern portion of Szél-anya Lineae. Because Szél-anya Lineae extends well beyond the region of more recent volcanic activity, the shield plains unit may represent passive magmatic activity where magma ascends through pre-fractured terrain created by the fracture belt unit. In contrast, the fracture belt unit associated with Laka Mons (lat $80^{\circ} \mathrm{N}$., long $265^{\circ}$ E., fig. $22 B$, on map) is a more local feature, extending only $\sim 200 \mathrm{~km}$ as compared to the $>1200 \mathrm{~km}$ length of Szél-anya Lineae, and it has a large shield volcano situated near the center of the belt. In this case, the fracture belt unit may have formed as a result of an actively ascending magma plume that also acted as the source for the eruptions that resulted in the formation of Laka Mons. The lobate plains unit associated with this volcano extends over the surrounding plains units, completely covering wrinkle ridges that deform the plains immediately adjacent to Laka Mons where the lava flows are interpreted to be thicker, and at least partially covering wrinkle ridges that deform the plains near the distal extent of the lobate plains where the flows are interpreted to be thinner. The stratigraphic trend that the observed lobate flows unit is stratigraphically the youngest feature observed is also consistent with observations of unit pla associated with Renpet Mons and Sarasvati Mons overlying other adjacent units.

While the lobate plains unit associated with Renpet Mons also covers surrounding plains units, unit pla has a somewhat more complex interaction with other volcanic units that lie on the flanks of this large volcano, including the edifice and shield plains units ed and psh 2 (fig. 23, on map). Three outcrops of the edifice unit are observed within V-1, including Eirene, Yansa, and Akka Tholi (as well as Thallo Mons that lies in the neighboring V-5 quadrangle, Rosenberg and McGill, 2001), and these features lie on the western side of Renpet Mons and appear to have formed concurrently with the unit pla materials from the larger shield volcano. Flows associated with Renpet Mons apparently form the foundation upon which the three smaller edifices lie, but later flows from Renpet Mons clearly are diverted by these smaller volcanoes. These observations indicate that Renpet Mons erupted several times, forming its present structure before the smaller edifices formed on its flanks. After the edifices formed, Renpet Mons continued to erupt, feeding flows that flowed around the newer volcanoes. 
The youngest volcanism in this area appears to be a cluster of small shields near the caldera of the large shield volcano, shields that fed flows covering the southeast section of the caldera.

An outcrop of lobate plains material, unit plb, is observed between Anahit Corona and Pomona Corona (fig. 18, on map). This unit appears to originate from linear fissure sources associated with Pomona Corona as opposed to a central source such as that observed with Renpet Mons, for example. These local flows superpose the surrounding regional plains units as well as the deformed materials associated with the corona annulus unit. Other plains units associated with all coronae observed in $\mathrm{V}-1$ include smooth, radar dark and radar bright coronae units (pcds, pcbs). These units are interpreted to form towards the final stages of coronae evolution, with the dark plains unit forming in the center of the raised corona plateau and the bright plains unit forming at the outer edges of the corona annulus unit. The deposition of the radar bright smooth coronae plains unit may be coeval with and (or) postdate the lobate plains unit associated with dikes that radiate from Pomona Corona (fig. 18, on map), though adjacent boundaries between these two units are not prevalent and thus these interpretations are not conclusive. The deposition of the radar dark smooth coronae plains unit occurred after the formation of the annulus and densely lineated plains units associated with the coronae, a trend that is apparent where deformation associated with these latter units is truncated at boundaries with the radar dark coronae plains unit. The superposition of these young flows over older coronae materials (for example, units an, pdl, ta) observed in the region indicates that the coronae formed over extended periods of time, consistent with other observations of coronae evolution (that is, Pronin and Stofan, 1990; Roberts and Head, 1993). The relatively young age of these flows indicates that coronae represent some of the most recently active features within $\mathrm{V}-1$.

\section{Geologic History}

The stratigraphy described above indicates that the observable geologic history of the north polar region of Venus can be characterized by a sequence of stress states that alternates between compressive and tensile. This sequence is consistent with interpretations for the most recent $10-20 \%$ of the geologic history of Venus in general, over which time deformation associated with the formation of tessera, followed by dense fracturing, then broad wrinkle ridging, and, finally, localized fracturing indicates a series of successive tectonic episodes consistent with first compressive, then tensile, then again compressive, and, finally, tensile stresses (for example, Basilevsky and Head, 1998; Head and Basilevsky, 1998; Basilevsky and Head, 2000). Overall activity and intensity of these tectonic episodes appears to decline over time as deformation resulting from each episode becomes more localized. The earliest activity observed in the Snegurochka Planitia (V-1) region consisted of the formation of tessera, a feature that is generally considered to have formed by early stages of compression-induced deformation such as folds and raised topography, followed by tension-induced deforma- tion such as grabens and ribbons within the now folded terrain (for example, Bindschadler and Head, 1991; Ivanov and Head, 1996; Hansen and Willis, 1998). This early compressive environment may have been the result of a combination of many factors including, for example, mantle overturn (for example, Parmentier and Hess, 1992), mantle convection (for example, ArkaniHamed, 1993; Phillips and Hansen, 1994), or episodic plate tectonics (for example, Turcotte, 1993). Alternative hypotheses for tessera formation include crustal thickening as the result of upwelling in a mantle plume (Hansen and others, 1997; Hansen and Willis, 1998), possibly resulting in the formation of a lava pond on the surface that cooled to form the observed tessera terrain (Hansen, 2006), though proposed evidence for these hypotheses is observed in Lakshmi Planitia (V-7), outside the Snegurochka Planitia (V-1) region. Also forming during an early stage of compression are densely lineated plains and ridged belts. Ridged belts in particular have been identified as compressional features that formed in response to the shortening of terrain due to regional stresses. In some locations, such as Lukelong Dorsa, crustal shortening leads to flexure and possible under-thrusting of plains and to the formation of a trough that runs parallel to the folded ridged belt (for example, Frank and Head, 1990). Observations indicate that ridged belt formation primarily occurred during this earlier period of regional compression, though some features such as Lukelong Dorsa may have been reactivated in a later episode of regional compression.

The next period of geologic activity involves the emplacement of the various episodes of regional and shield plains materials and is thus interpreted to represent a broad tensile stress field. While the regional deformed and radar dark smooth plains units are likely similar to flood basalts, individual source vents for the more localized radar bright smooth plains units have yet to be identified. We observe that these vents will take on the form of small vents and fissures that were either subsequently covered by the volcanic plains or are too small to be identified with available data. These interpreted fissures would have resulted from regional tensile stresses, feeding widespread volcanism at rates on the order of a few $\mathrm{km}^{3} \mathrm{y}-1$ (for example, Basilevsky and Head, 1996). These episodes of regional plains emplacement are stratigraphically distinct, but with such high extrusion rates they may have been emplaced within a relatively short period of time (10-100 m.y.) in the geologic history of Venus (that is, Herrick, 1994; Strom and others, 1994; Basilevsky and Head, 1996).

Additional evidence for extension during this period is observed in fissures associated with coronae. Many fissures associated with Anahit Corona and Maslenitsa Corona have been at least partially covered by subsequent regional plains emplacement, indicating that these fissures formed throughout this earlier period of regional volcanic activity. Corona annuli may also have formed during this time in the history of $\mathrm{V}-1$ before being subsequently embayed by continued emplacement of regional plains. The end of this period marks the end of widespread regional volcanism observed in this region of Venus, an observation that is consistent with interpretations of volcanism for the rest of the planet (for example, Basilevsky and Head, 1998), indicating a broad shift in volcanic activity at this time in the geologic history of Venus. 
The plains emplaced during this time were subsequently subjected to compressive tectonic deformation during the next period of geologic activity. The stresses that characterize this compressive period are thought to have been more localized, as the wrinkle ridges that are interpreted to have formed during this period are concentrated primarily within Louhi Planitia and possibly coincide with a reactivation of ridged belt formation in Lukelong Dorsa. This period is interpreted to have been relatively brief or of low intensity, as the wrinkle ridges locally deform a single unit (dark smooth regional plains), suggesting that the stress field was not strong enough to deform older, more stable material such as tessera or ridged belts, nor was it present for enough time to deform younger material such as fracture belts, lobate plains, or the youngest shield plains that were emplaced later.

The most recent observed period of geologic activity shifts to a tensile stress regime and is characterized by fracture belt formation and volcanism associated with large shield volcanoes and coronae, with localized extension occurring both in Louhi Planitia with the formation of Szél-anya Lineae and in Snegurochka Planitia with the formation of Renpet Mons, Laka Mons, and the continued formation of Pomona Corona. While some volcanism may have resulted from passive ascent through pre-fractured terrain (for example, the shield plains present at the northern extent of Szél-anya Lineae), other volcanism likely occurred due to the active ascent of a magma plume (for example, Renpet Mons, Laka Mons, and fissures associated with Pomona Corona). These observations and interpretations indicate that magma plumes and rifting were active more recently than other processes observed in this region.

The geologic history described above closely mirrors many interpretations for the geologic history of Venus as a whole (Basilevsky and Head, 1995; Basilevsky and others, 1997). Observations made in this quadrangle do not support an alternative interpretation of the geologic history of Venus that involves a more random temporal distribution of feature formation, with features such as coronae, rifts, large and small shield volcanoes, and regional volcanic plains forming throughout the history of the region (that is, Guest and Stofan, 1999). While the periods of compressive and tensile activity are not correlated to terrestrial events, they appear to have occurred globally on Venus as well as on the Moon, Mercury, and Mars (Head and Solomon, 1981). Further investigations and modeling may indicate that early Earth underwent similar periods of activity, but as Earth developed plate tectonics and an oxygen-enriched atmosphere, the geologic history of the Earth diverged from that of Venus. By continuing to study the stratigraphy of Venus, we may be better equipped to understand the early evolution of the Earth and why the later geologic histories of the two planets differ.

\section{References Cited}

Arkani-Hamed, J., 1993, On the thermal evolution of Venus: Journal of Geophysical Research, v. 99, no. E1, p. 20192033.
Arvidson, R.E., Plaut, J.J., Jurgens, R.F., and 2 others, 1990, Geology of Southern Guinevere Planitia, Venus, Based on analysis of Goldstone radar data: 20th Lunar and Planetary Science Conference, p. 557-572.

Arvidson, R.E., Baker, V.R., Elachi, C., and 2 others, 1991, Magellan: Initial analysis of Venus surface modification: Science, v. 252, p. 270-275.

Baker, V.R., Komatsu, G., Parker, T.J., Gulick, and 3 others, 1992, Channels and valleys on Venus - Preliminary analysis of Magellan data: Journal of Geophysical Research, v. 97, no. E8, p. 13,421-13,444.

Barsukov, V.L., 1986, Basilevsky, A.T., Burba, G.A., Bobina, N.N., and 29 others, The geology and geomorphology of the Venus surface as revealed by the radar images obtained by Veneras 15 and 16: 16th Lunar and Planetary Science Conference, p. 378-398.

Basilevsky, A.T., 1986, Structure of central and eastern areas of Ishtar Terra and some problems of Venusian tectonics: NASA Tech. Memo., TM-88508, translated from Geotektonika, 1986, v. 20, p. 282-288.

Basilevsky, A.T., 2008, Geologic map of the Beta Regio Quadrangle (V-17), Venus: U.S. Geological Survey Geologic Investigations Series Map I-3023, scale 1:5,000,000.

Basilevsky, A.T., and Head, J.W., 1988, The geology of Venus: Annual Review of Earth and Planetary Sciences, v. 16, p. 295-317.

Basilevsky, A.T., and Head, J.W., 1995, Regional and global stratigraphy of Venus-A preliminary assessment and implications for the geological history of Venus: Planetary and Space Science, v. 43, p. 1523-1553.

Basilevsky, A.T., and Head, J.W., 1996, Evidence for rapid and widespread emplacement of volcanic plains on VenusStratigraphic studies in the Baltis Vallis Region: Geophysical Research Letters, v. 23, no. 12, p. 1497-1500.

Basilevsky, A.T., and Head, J.W., 1998, The geologic history of Venus - A stratigraphic view: Journal of Geophysical Research, v. 103, no. E4, 8531-8544.

Basilevsky, A.T., and Head, J.W., 2000, Geologic units on Venus-Evidence for their global correlation: Planetary and Space Science, v. 48, no. 1, p. 75-111.

Basilevsky, A.T., Head, J.W., Schaber, G.G., and Strom, R.G., 1997, The resurfacing history of Venus, in Bougher, S.W., Hunten, D.M., and Philips, R.J., eds., Venus II: Geology, Geophysics, Atmosphere, and Solar Wind Environment: University of Arizona Press, p. 1047.

Basilevsky, A.T., Pronin, A.A., Ronca, L.B., and 3 others, 1986, Styles of tectonic deformations on Venus-Analysis of Venera 15 and 16 data: 16th Lunar and Planetary Science Conference, 399-411.

Bilotti, F., and Suppe, J., 1999, The global distribution of wrinkle ridges on Venus: Icarus, v. 139, p. 137-157.

Bindschadler, D.L., 1995, Magellan-A new view of Venus' geology and geophysics: Reviews of Geophysics, v. 33, p. 459-468.

Bindschadler, D.L., and Head, J.W., 1991, Tessera terrain, Venus - Characterization and models for origin and evolution: Journal of Geophysical Research, v. 96, no. B4, p. 5889-5907. 
Bindschadler, D.L., and Parmentier, E.M., 1990, Mantle flow tectonics: The influence of a ductile lower crust and implications for the formation of topographic uplands on Venus: Journal of Geophysical Research, v. 95, p. 21,329-21,344.

Bindschadler, D.L., Schubert, G., and Kaula, W.M., 1990, Mantle flow tectonics and the origin of Ishtar Terra, Venus: Geophysical Research Letters, v. 17, p. 1345-1348.

Bridges, N.T., 1995, Submarine analogs to Venusian pancake domes: Geophysical Research Letters, v. 22, no. 20, p. 2781-2784.

Bridges, N.T., and McGill, G.E., 2002, Geologic map of the Kaiwan Fluctus Quadrangle (V-44), Venus: U.S. Geological Survey Geologic Investigations Series Map I-2747, scale 1:5,000,000.

Bulmer, M.H., and Guest, J.E., 1996, Modified domes and associated debris apron on Venus, in McGuire, J.W., Jones, A.P., and Neuberg, J., eds., Volcano instability on the Earth and other planets: Geological Society Special Publication, v. 110, p. 349-371.

Campbell, B.A., 1999, Surface formation rates and impact crater densities on Venus: Journal of Geophysical Research, v. 104, no. E9, p. 21,951-21,956.

Campbell, B.A., and Campbell, P.G., 2002, Geologic map of the Bell Regio Quadrangle (V-9), Venus: U.S. Geological Survey Geologic Investigations Series Map I-2743, scale 1:5,000,000.

Campbell, D.B., and Burns, B.A., 1980, Earth-based radar imagery of Venus: Journal of Geophysical Research, v. 85, p. 8271-8281.

Campbell, D.B., Stacy, N.J.S., Newman, W.I., and 5 others, 1992, Magellan observations of extended impact crater related features on the surface of Venus: Journal of Geophysical Research, v. 97, no. E10, p. 16,249-16,277.

Crumpler, L.S., and Aubele, J.C., 2000, Volcanism on Venus, in Sigurdsson, H., (ed.), Encyclopedia of volcanoes: San Diego, Academic Press, p. 727-769.

Ernst, R.E., Desnoyers, D.W., Head, J.W., and Grosfils, E.B., 2003, Graben-fissure systems in Guinevere Planitia and Beta Regio $\left(264^{\circ}-312^{\circ}\right.$ E., $24^{\circ}-60^{\circ}$ N.), Venus, and implications for regional stratigraphy and mantle plumes: Icarus, v. 164, p. 282-316.

Ernst, R.E., Grosfils, E.B., and Mége, D., 2001, Giant dike swarms - Earth, Venus, and Mars: Annual Review of Earth and Planetary Sciences, v. 29, p. 489.

Farr, T.G., 1993, Radar interactions with geologic surfaces, in Ford, J.P., and 7 others, (eds.), Guide to Magellan Image Interpretation: Pasadena, Calif., JPL and California Institute of Technology Publication 93-24, p. 45-56.

Frank, S.L., and Head, J.W., 1990, Ridge belts on Venus-Morphology and origin: Earth, Moon, and Planets, v. 50-51, no. 1, p. $421-470$.

Ford, J.P., Blom, R.G., Crisp, J.A., and 6 others, 1989, Spaceborne radar observations - A guide for Magellan radarimage analysis: Pasadena, Calif., JPL and California Institute of Technology Publication 89-41.

Ford, J.P., Plaut, J.J., Weitz, C.M., and 5 others, 1993, Guide to Magellan image interpretation: Pasadena, Calif., JPL and California Institute of Technology Publication 93-24.
Ford, P.G., and Pettengill, G.H., 1992, Venus topography and kilometer-scale slopes: Journal of Geophysical Research, v. 97, E8, p. 13,103-13,114.

Greeley, R., Bender, K., Thomas, P.E., and 3 others, 1995, Wind-related features and processes on Venus - Summary of Magellan results: Icarus, v. 115, no. 2, p. 399-420.

Grosfils, E.B., and Head, J.W., 1994, Emplacement of a radiating dike swarm in western Vinmara Planitia, Venusinterpretation of the regional stress field orientation and subsurface magmatic configuration: Earth, Moon, and Planets, v. 66, p. 153-171.

Guest, J.E., and Stofan, E.R., 1999, A new view of the stratigraphic history of Venus: Icarus, v. 139, no. 1, p. 55-66.

Hansen, V.L., 2006, Geologic constraints on crustal plateau surface histories, Venus - The lava pond and bolide impact hypotheses: Journal of Geophysical Research-Planets, v. 111, doi:10.1029/2006JE002714.

Hansen, V.L., Phillips, R.J., Willis, J.J., and Ghent, R.R., 2000, Structures in tessera terrain, Venus-Issues and answers: Journal of Geophysical Research, v. 105, no. E2, p. 4135-4152.

Hansen, V.L., and Willis, J.J., 1998, Ribbon terrain formation, southwestern Fortuna Tessera, Venus-Implications for lithosphere evolution: Icarus, v. 132, no. 2, p. 321-343.

Hansen, V.L., Willis, J.J., and Banerdt, W.B., 1997, Tectonic overview and synthesis, in Bougher, S.W., Hunten, D.M., and Phillips, R.J., eds., Venus II-Geology, Geophysics, Atmosphere, and Solar Wind Environment: University of Arizona Press, p. 797-844.

Hauck, S.A., II, Phillips, R.J., and Price, M.H., 1998, VenusCrater distribution and plains resurfacing models: Journal of Geophysical Research, v. 103, no. E6, p. 13,635-13,642.

Head, J.W., and Basilevsky, A.T., 1998, Sequence of tectonic deformation in the history of Venus-Evidence from global stratigraphic relationships: Geology, v. 26, no. 1, p. 35-38.

Head, J.W., Campbell, D.B., Elachi, C.H.A.R., and 5 others, 1991, Venus volcanism-Initial analysis from Magellan Data: Science, v. 252, p. 276-288.

Head, J.W., Crumpler, L., Aubele, J., and 2 others, 1992, Venus volcanism - Classification of volcanic features and structures, associations, and global distribution from Magellan data: Journal of Geophysical Research, v. 97, no. E8, p. 13,153-13,197.

Head, J.W., and Solomon, S.C., 1981, Tectonic evolution of the terrestrial planets: Science, v. 213, p. 62-76.

Head, J.W., Wilson, L., and Smith, D.K., 1996, Mid-ocean ridge eruptive vent morphology and substructure-Evidence for dike widths, eruption rates, and evolution of eruptions and axial volcanic ridges: Journal of Geophysical Research, v. 101, no. B12, p. 28,265-28,280.

Herrick, R.R., 1994, Resurfacing history of Venus: Geology, v. 22, no. 8, p. 703-706.

Ivanov, M.A., and Head, J.W., 1996, Tessera terrain on VenusA survey of the global distribution, characteristics, and relation to surrounding units from Magellan data: Journal of Geophysical Research, v. 101, no. E6, p. 14,861-14,908. Ivanov, M.A., and Head, J.W., 2001, Geology of Venus-Map- 
ping of a global geotraverse at $30 \mathrm{oN}$ latitude: Journal of Geophysical Research, v. 106, no. E8, p. 17,515-17,566.

Ivanov, M.A., and Head, J.W., 2004a, Stratigraphy of small shield volcanoes on Venus - Criteria for determining stratigraphic relationships and assessment of relative age and temporal abundance: Journal of Geophysical Research, v. 109, doi: 10.1029/2004JE002252.

Ivanov, M.A., and Head, J.W., 2004b, Geologic map of the Atalanta Planitia Quadrangle (V-4), Venus: U.S. Geological Survey Geologic Investigations Map I-2792, scale $1: 5,000,000$.

Ivanov, M.A., and Head, J.W., 2008, Geologic map of the Meskhent Tessera Quadrangle (V-3), Venus: U.S. Geological Survey Scientific Investigations Map 3018, scale $1: 5,000,000$.

Ivanov, M.A., and Head, J.W., 2009, Geologic map of the Lakshmi Planum Quadrangle (V-7), Venus: U.S. Geological Survey USGS Scientific Investigations Map 3116.

Ivanov, B.A., Nemchinov, I.V., Svetsov, V.A., and 3 others, 1992, Impact cratering on Venus - Physical and mechanical models: Journal of Geophysical Research, v. 97, no. E10, p. 16,167-16,181.

Janes, D.M., Squyres, S.W., Bindschadler, D.L., and 4 others, 1992, Geophysical models for the formation and evolution of coronae on Venus: Journal of Geophysical Research, v. 97, no. E10, p. 16,055-16,067.

Jonsson, S., Zebker, H., Cervelli, P., and 4 others, 1999, A shallow-dipping dike fed the 1995 flank eruption at Fernandina volcano, Galapagos, observed by satellite radar interferometry: Geophysical Research Letters, v. 26, no. 8, p. 1077-1080.

Jurgens, R.F., Franck, C., Greiner, W., and 6 others, 1990, Radar observations of Tinatin Planitia-Goldstone 1988 observations of Venus: 21st Lunar and Planetary Science Conference, p. 593.

Jurgens, R.F., Goldstein, R.M., Rumsey, H.R., and Green, R.R., 1980, Images of Venus by three-station radar interferometry, 1977 results: Journal of Geophysical Research, v. 85, no. A13, p. 8282-8294.

Kargel, J.S., Komatsu, G., Baker, V.R., and Strom, R.G., 1993, The volcanology of Venera and VEGA landing sites and the geochemistry of Venus: Icarus, v. 103, no. 2, p. 253-275.

Kaula, W.M., 1995, Venus reconsidered: Science, v. 270, p. 1460-1464.

Kaula, W.M., Owen, T., Runcorn, S.K., and Tozer, D.C., 1994, The tectonics of Venus [and discussion]: Philosophical Transactions: Physical Sciences and Engineering, v. 349, p. 345-355.

Kotelnikov, V.A. and 15 others, 1989, Atlas of Venus: Moscow, former Soviet Union (in Russian).

Kozak, R.C., and Schaber, G.G., 1986, Gravity-spreading origin of the Venusian tessera: 17th Lunar and Planetary Science Conference, p. 444-445.

Kreslavsky, M.A., and Head, J.W., 1999, Morphometry of small shield volcanoes on Venus - Implications for the thickness of regional plains: Journal of Geophysical Research, v. 104, p. 18,925-18,932.
Kryuchkov, V.P., 1990, Ridge belts-Are they compressional or extensional structures?: Earth Moon and Planets, v. 50-51, p. 471-491.

Masursky, H., Eliason, E., Ford, P.G., and 4 others, 1980, Pioneer Venus radar results - Geology from images and altimetry: Journal of Geophysical Research, v. 85, no. A13, p. $8232-8260$.

McGill, G.E., 2000, Geologic map of the Sappho Patera Quadrangle (V-20), Venus: U.S. Geological Survey Geologic Investigations Series Map I-2637, scale 1:5,000,000.

Namiki, N., and Solomon, S.C., 1994, Impact crater densities on volcanoes and coronae on Venus - Implications for volcanic resurfacing: Science, v. 265, p. 929-933.

Nimmo, F., and McKenzie, D., 1998, Volcanism and tectonics on Venus: Annual Review of Earth and Planetary Sciences, v. 26 , no. 1, p. 23.

Parmentier, E.M., and Hess, P.C., 1992, Chemical differentiation of a convecting planetary interior-Consequences for a one plate planet such as Venus: Geophysical Research Letters, v. 19 no. 20, p. 2015-2018.

Pavri, B., Head, J.W. III, Klose, K.B., and Wilson, L., 1992 , Steep-sided domes on Venus - Characteristics, geologic setting, and eruption conditions from Magellan data: Journal of Geophysical Research, v. 97, no. E8, p. 13,44513,478 .

Pettengill, G.H., Eliason, E., Ford, P.G., and 3 others, 1980, Pioneer Venus radar results, altimetry, and surface properties: Journal of Geophysical Research, v. 85, no. A13, p. 8261-8270.

Phillips, R.J., Arvidson, R.E., Boyce, J.M., and 4 others, 1991, Impact craters on Venus-Initial analysis from Magellan: Science, v. 252, p. 288-297.

Phillips, R.J., and Hansen, V.L., 1994, Tectonic and magmatic evolution of Venus: Annual Review of Earth and Planetary Sciences, v. 22, no. 1, p. 597-656.

Phillips, R.J., and Hansen, V.L., 1998, Geological evolution of Venus-Rises, plains, plumes, and plateaus: Science, v. 279, p. 1492-1497.

Phillips, R.J., Raubertas, R.F., Arvidson, R.E., and 4 others, 1992, Impact craters and Venus resurfacing history: Journal of Geophysical Research, v. 97, no. E10, p. 15,923-15,948.

Plaut, J.J., and Arvidson, R.E., 1992, Comparison of Goldstone and Magellan radar data in the equatorial plains of Venus: Journal of Geophysical Research, v. 97, p. 16,279-16,291.

Pronin, A.A., 1986, The structure of Lakshmi Planum, an indication of horizontal asthenospheric flows on Venus: Geotectonics, v. 20, p. 271-281.

Pronin, A.A., and Stofan, E.R., 1990, Coronae on Venus-Morphology, classification, and distribution: Icarus, v. 87, no. 2, p. $452-474$.

Roberts, K.M., and Head, J.W., 1993, Large-scale volcanism associated with coronae on Venus-Implications for formation and evolution: Geophysical Research Letters, v. 20, no. 12 , p. 1111-1114.

Rosenberg, E., and McGill, G.E., 2001, Geologic map of the Pandrosos Dorsa Quadrangle (V-5), Venus: U.S. Geological Survey Geologic Investigations Series Map I-2721, scale 1:5,000,000. 
Saunders, R.S., Spear, A.J., Allin, P.C., and 24 others, 1992, Magellan mission summary: Journal of Geophysical Research, v. 97, no. E8, p. 13,067-13,090.

Schaber, G.G., Strom, R.G., Moore, H.J., and 7 others, 1992, Geology and distribution of impact craters on VenusWhat are they telling us?: Journal of Geophysical Research, v. 97, no. E8, p. 13,257-13,301.

Schultz, P.H., 1992, Atmospheric effects on ejecta emplacement and crater formation on Venus from Magellan: Journal of Geophysical Research, v. 97, no. E10, p. 16,183-16,248.

Simons, M., Solomon, S.C., and Hager, B.H., 1997, Localization of gravity and topography - Constraints on the tectonics and mantle dynamics of Venus: Geophysical Journal International, v. 131, p. 24-31.

Smerkar, S.E., and Phillips, R.J., 1988, Gravity-driven deformation of the crust of Venus: Geophysical Research Letters, v. 15, p. 693-696.

Smrekar, S.E., and Stofan, E.R., 1997, Corona formation and heat loss on Venus by coupled upwelling and delamination: Science, v. 277, p. 1289-1294.

Solomon, S.C., 1993, A tectonic resurfacing model for Venus: 24th Lunar and Planetary Science Conference, p. 13311332.

Solomon, S.C., Smrekar, S.E., Bindschadler, D.L., and 8 others, 1992, Venus tectonics - An overview of Magellan observations: Journal of Geophysical Research, v. 97, no. E8, p. 13,199-13,255.

Squyres, S.W., Janes, D.M., Baer, G., and 4 others, 1992b, The morphology and evolution of coronae on Venus: Journal of Geophysical Research, v. 97, no. E8, p. 13,611-13,634.

Squyres, S.W., Jankowski, D.G., Simons, M., and 3 others, 1992a, Plains tectonism on Venus - The deformation belts of Lavinia Planitia: Journal of Geophysical Research, v. 97, no. E8, p. 13,579-13,599.

Stofan, E.R., and Guest, E.G., 2003, Geologic map of the Aino Planitia Quadrangle (V-46), Venus: U.S. Geological Survey Geologic Investigations Series Map I-2779, scale $1: 5,000,000$.

Stofan, E.R., and Head, J.W., 1990, Coronae of Mnemosyne Regio-Morphology and origin: Icarus, v. 83, no. 1, p. 216-243.

Stofan, E.R., Head, J.W., Campbell, D.B., and 5 others, 1989,
Geology of a rift zone on Venus - Beta Regio and Devana Chasma: Geological Society of America Bulletin, v. 101, no. 1, p. 143-156.

Stofan, E.R., Anderson, S.W., Crown, D.A., and Plaut, J.J., 2000, Emplacement and composition of steep-sided domes on Venus: Journal of Geophysical Research, v. 105, no. E11, p. 26,757-26,771.

Stofan, E.R., Sharpton, V.L., Schubert, G., and 4 others, 1992, Global distribution and characteristics of coronae and related features on Venus - Implications for origin and relation to mantle processes: Journal of Geophysical Research, v. 97, no. E8, p. 13,347-13,378.

Strom, R.G., Schaber, G.G., and Dawson, D.D., 1994, The global resurfacing of Venus: Journal of Geophysical Research, v. 99, no. E5, p. 13,899-13,926.

Sukhanov, A.L., 1986, Parquet-Regions of areal plastic dislocations: Geotectonics, v. 20, p. 294-305.

Sukhanov, A.L., 1992, Tesserae, in Venus geology, geochemistry, and geophysics - Research results from the USSR: Tucson, Ariz., University of Arizona Press, p. 82-95.

Sukhanov, A.L., and Schubert, G., 1989, Ridged belts on Venus as extensional features: 19th Lunar and Planetary Science Conference, p. 335-348.

Surkov, Y., Moskalyova, L.P., Kharyukova, V.P., and 3 others, 1986, Venus rock composition at the Vega 2 landing site: Journal of Geophysical Research, v. 91, no. B13, p. 215-218.

Tanaka, K.L., 1994, Venus geologic mappers' handbook, 2d ed.: U.S. Geological Survey Open-File Report 94-438, p. 50.

Turcotte, D.L., 1993, An episodic hypothesis for Venusian tectonics: Journal of Geophysical Research, v. 98, no. E9, p. 17,061-17,068.

Tyler, G.L., Simpson, R.A., Maurer, M.J., and Holmann, E., 1992, Scattering properties of the Venusian surface-Preliminary results from Magellan: Journal of Geophysical Research, v. 97, no. E8, p. 13,115-13,139.

Wilhelms, D.E., 1990, Geologic mapping, in Planetary mapping: Cambridge, GB, Cambridge University Press, p. 208.

Wilson, L., 2001, Evidence for episodicity in the magma supply to the large Tharsis volcanoes: Journal of Geophysical Research, v. 106, no. E1, p. 1423-1434. 
Table 1. Impact craters in V-1.

\begin{tabular}{|c|c|c|c|c|c|c|c|c|c|c|c|}
\hline $\begin{array}{l}\text { Crater } \\
\text { ID }\end{array}$ & $\begin{array}{l}\text { Crater } \\
\text { Name }\end{array}$ & Latitude & Longitude & $\begin{array}{l}\text { Diameter } \\
(\mathbf{k m})\end{array}$ & $\begin{array}{l}\text { Crater } \\
\text { Type }^{1}\end{array}$ & Degradation $^{2}$ & $\begin{array}{l}\text { Superposed } \\
\text { by }\end{array}$ & Superposing & $\begin{array}{l}\text { Central peak } \\
\text { present? }\end{array}$ & Infill material & Ejecta character \\
\hline 1 & unnamed & 80.9 & 226.4 & 2.9 & Simple & Degraded & pdd & - & no & $\begin{array}{l}\text { Radar dark } \\
\text { material }\end{array}$ & Unobserved \\
\hline 2 & Tursunoy & 80.9 & 229.3 & 4.5 & Simple & Degraded & pbd & - & no & $\begin{array}{l}\text { Radar dark } \\
\text { material }\end{array}$ & Partly embayed \\
\hline 3 & $\begin{array}{l}\text { unnamed } \\
\text { cluster }\end{array}$ & 80 & 229.7 & $\begin{array}{l}5.7,7.5 \\
5.0\end{array}$ & Simple & Degraded & pdd/pdl & - & no & $\begin{array}{l}\text { Radar dark } \\
\text { material }\end{array}$ & $\begin{array}{l}\text { Diffuse; } \\
\text { crater cluster (x3) }\end{array}$ \\
\hline 4 & Eugenia & 80.6 & 105.5 & 6 & Simple & $\begin{array}{l}\text { Somewhat } \\
\text { fresh }\end{array}$ & - & $\mathrm{pdd} / \mathrm{wr}$ & no & $\begin{array}{l}\text { Radar dark } \\
\text { material }\end{array}$ & Clear ejecta; possible cluster \\
\hline 5 & Janice & 87.3 & 262.4 & 11.9 & Transition & $\begin{array}{l}\text { Somewhat } \\
\text { degraded }\end{array}$ & - & $\mathrm{pbd} / \mathrm{pdd} / \mathrm{fb}$ & yes, small & $\begin{array}{l}\text { Radar dark } \\
\text { material }\end{array}$ & Diffuse \\
\hline 6 & Radka & 75.6 & 96.3 & 13.1 & Transition & $\begin{array}{l}\text { Somewhat } \\
\text { degraded }\end{array}$ & $\operatorname{lin}$ & $\mathrm{pdd} / \mathrm{pbs}$ & yes, small & $\begin{array}{l}\text { Not signifi- } \\
\text { cantly infilled }\end{array}$ & Partly embayed \\
\hline 7 & Gina & 78.1 & 76.5 & 14.7 & Transition & $\begin{array}{l}\text { Somewhat } \\
\text { degraded }\end{array}$ & - & $\mathrm{fb} / \mathrm{pds} / \mathrm{pbs}$ & maybe & $\begin{array}{l}\text { Radar bright } \\
\text { material }\end{array}$ & $\begin{array}{l}\text { Partly embayed, visible only on } \\
\text { pds }\end{array}$ \\
\hline 9 & Valborg & 75.5 & 272.1 & 19.2 & Complex & Degraded & - & pbs & yes & $\begin{array}{l}\text { Radar dark } \\
\text { material }\end{array}$ & Mostly embayed \\
\hline 10 & Ulrique & 75.9 & 55.6 & 19.3 & Complex & Fresh & - & pdd & yes & $\begin{array}{l}\text { Partly infilled } \\
\text { with radar dark } \\
\text { material }\end{array}$ & Clear ejecta \\
\hline 11 & Fernandez & 76.2 & 17.2 & 20.4 & Complex? & $\begin{array}{l}\text { Somewhat } \\
\text { fresh }\end{array}$ & - & $\mathrm{pds} / \mathrm{pdl} / \mathrm{ta}$ & no & $\begin{array}{l}\text { Radar dark } \\
\text { material }\end{array}$ & Mostly embayed \\
\hline 12 & Odilia & 81.2 & 200.3 & 21.6 & Complex & $\begin{array}{l}\text { Heavily } \\
\text { degraded }\end{array}$ & $\mathrm{rb} / \mathrm{pbs} / \mathrm{pds}$ & - & no & $\begin{array}{l}\text { Partly infilled } \\
\text { with radar } \\
\text { bright material }\end{array}$ & Uneven, deformed by rb \\
\hline 13 & Tatyana & 85.4 & 214.6 & 21.8 & Simple & $\begin{array}{l}\text { Somewhat } \\
\text { degraded }\end{array}$ & $\mathrm{rb} / \mathrm{pds} / \mathrm{wr}$ & - & yes & $\begin{array}{l}\text { Radar bright } \\
\text { material }\end{array}$ & Uneven, partly deformed by rb \\
\hline 14 & Sveta & 82.5 & 273.2 & 22.3 & Simple? & Fresh & - & $\mathrm{pbs} / \mathrm{pdd} / \mathrm{pbs} / \mathrm{lin}$ & yes, small & $\begin{array}{l}\text { Partly infilled } \\
\text { with radar dark } \\
\text { material }\end{array}$ & Unembayed, covers lin \\
\hline 16 & Hua Mulan & 86.8 & 337.5 & 27.5 & Complex & Degraded & $\mathrm{pdd} / \mathrm{psh}_{1} / \mathrm{lin}$ & - & maybe & $\begin{array}{l}\text { Radar dark } \\
\text { material }\end{array}$ & Mostly embayed \\
\hline 17 & Rudneva & 78.4 & 174.7 & 31.3 & Complex & Fresh & - & pds & yes & $\begin{array}{l}\text { Radar dark } \\
\text { material }\end{array}$ & Clear, unembayed \\
\hline
\end{tabular}


Table 1. Impact craters in V-1-continued.

\begin{tabular}{|c|c|c|c|c|c|c|c|c|c|c|c|}
\hline $\begin{array}{l}\text { Crater } \\
\text { ID }\end{array}$ & $\begin{array}{l}\text { Crater } \\
\text { Name }\end{array}$ & Latitude & Longitude & $\begin{array}{l}\text { Diameter } \\
\quad(\mathrm{km})\end{array}$ & $\begin{array}{l}\text { Crater } \\
\text { Type }^{1}\end{array}$ & Degradation ${ }^{2}$ & $\begin{array}{l}\text { Superposed } \\
\text { by }\end{array}$ & Superposing & $\begin{array}{l}\text { Central peak } \\
\text { present? }\end{array}$ & Infill material & Ejecta character \\
\hline 18 & Landowska & 84.6 & 76.9 & $\sim 37.6$ & Complex & Degraded & $\mathrm{rb} / \mathrm{pdd} / \mathrm{pds}$ & - & yes & $\begin{array}{l}\text { Radar bright } \\
\text { material }\end{array}$ & Embayed and deformed \\
\hline 19 & Ruslanova & 84 & 16.5 & $\sim 43.0$ & Complex & Fresh & - & $\mathrm{fb} / \mathrm{pdl} / \mathrm{pds}$ & yes & $\begin{array}{l}\text { Radar bright } \\
\text { material }\end{array}$ & Unembayed \\
\hline 20 & Volkova & 75.2 & 242.2 & 46.9 & Complex & Fresh & - & $\mathrm{pla} / \mathrm{pdl} / \mathrm{pbs}$ & yes & $\begin{array}{l}\text { Radar dark } \\
\text { material super- } \\
\text { posed by radar } \\
\text { bright material }\end{array}$ & $\begin{array}{l}\text { Unembayed, impact melt depos- } \\
\text { its evident }\end{array}$ \\
\hline 21 & Dashkova & 78.2 & 306.5 & 52.3 & Complex & $\begin{array}{l}\text { Heavily } \\
\text { degraded }\end{array}$ & - & an/pds/pbs/ta & Yes & $\begin{array}{l}\text { Radar bright } \\
\text { material }\end{array}$ & Uneven ejecta on slope of unit ta \\
\hline 22 & Lagerlof & 81.2 & 285.1 & 59.8 & Complex & Degraded & $\mathrm{pdd} / \mathrm{pds}$ & - & $\begin{array}{l}\text { Minor } \\
\text { central peak } \\
\text { cluster }\end{array}$ & $\begin{array}{l}\text { Radar dark } \\
\text { material }\end{array}$ & Mostly embayed \\
\hline 23 & Klenova & 78.2 & 104.7 & 143.5 & $\begin{array}{l}\text { Compound } \\
\text { complex }\end{array}$ & Fresh & - & $\mathrm{pds} / \mathrm{pbs} / \mathrm{wr}$ & $\begin{array}{l}\text { Multi-ring } \\
\text { basin }\end{array}$ & $\begin{array}{l}\text { Radar dark } \\
\text { material in } \\
\text { interior, sur- } \\
\text { rounded by } \\
\text { multiple basin } \\
\text { rings }\end{array}$ & $\begin{array}{l}\text { Unembayed, secondary craters } \\
\text { evident }\end{array}$ \\
\hline
\end{tabular}

${ }^{1}$ Crater types: simple craters are bowl-shaped, typically smaller diameter craters; transition craters have a small central peak; complex craters have prominent central peaks or central peak clusters; compound complex craters have concentric rings, largest diameter craters.

2Degradation of craters include 1) fresh craters, where ejecta deposits are observed to cover surrounding units and structures, 2) somewhat fresh craters, where the majority of the ejecta deposits overly surrounding units but might be partially embayed, 3) somewhat degraded craters, where ejecta deposits are visible but are deformed by surrounding structures, 4) degraded craters, where ejecta deposits are significantly embayed or

modified by surrounding units and structures, and 5) heavily degraded, where ejecta deposits are completely embayed or crater rims are modified by surrounding structures. 
Table 2. Area of units mapped in V-1.

\begin{tabular}{lcc}
\hline \multicolumn{1}{c}{ Unit } & Label & Percent Area* \\
\hline Undifferentiated crater material & c & 1.7 \\
Edifice unit & ed & 0.11 \\
Lobate plains unit a, point source & pla & 3.6 \\
Lobate plains unit b, linear source & plb & 0.3 \\
Dark smooth corona plains material & pcds & 0.6 \\
Bright smooth corona plains material & pcbs & 2.8 \\
Fracture belt material & fb & 3.1 \\
Bright smooth regional plains material & pbs & 7.2 \\
Dark smooth regional plains material & pds & 23 \\
Bright deformed corona plains material & pcbd & 0.85 \\
Upper shield plains material & psh2 & 0.04 \\
Lower shield plains material & psh1 & 4.0 \\
Bright deformed regional plains material & pbd & 12 \\
Dark deformed regional plains material & pdd & 14 \\
Annulus unit & an & 1.5 \\
Ridged belt unit & rb & 6.6 \\
Densely lineated plains material & pdl & 14 \\
Tessera unit a & ta & 4.4 \\
Tessera unit b & tb & 0.2 \\
\hline
\end{tabular}

*Total area in V-1: $6.6 \times 10^{6} \mathrm{~km}^{2}$ 


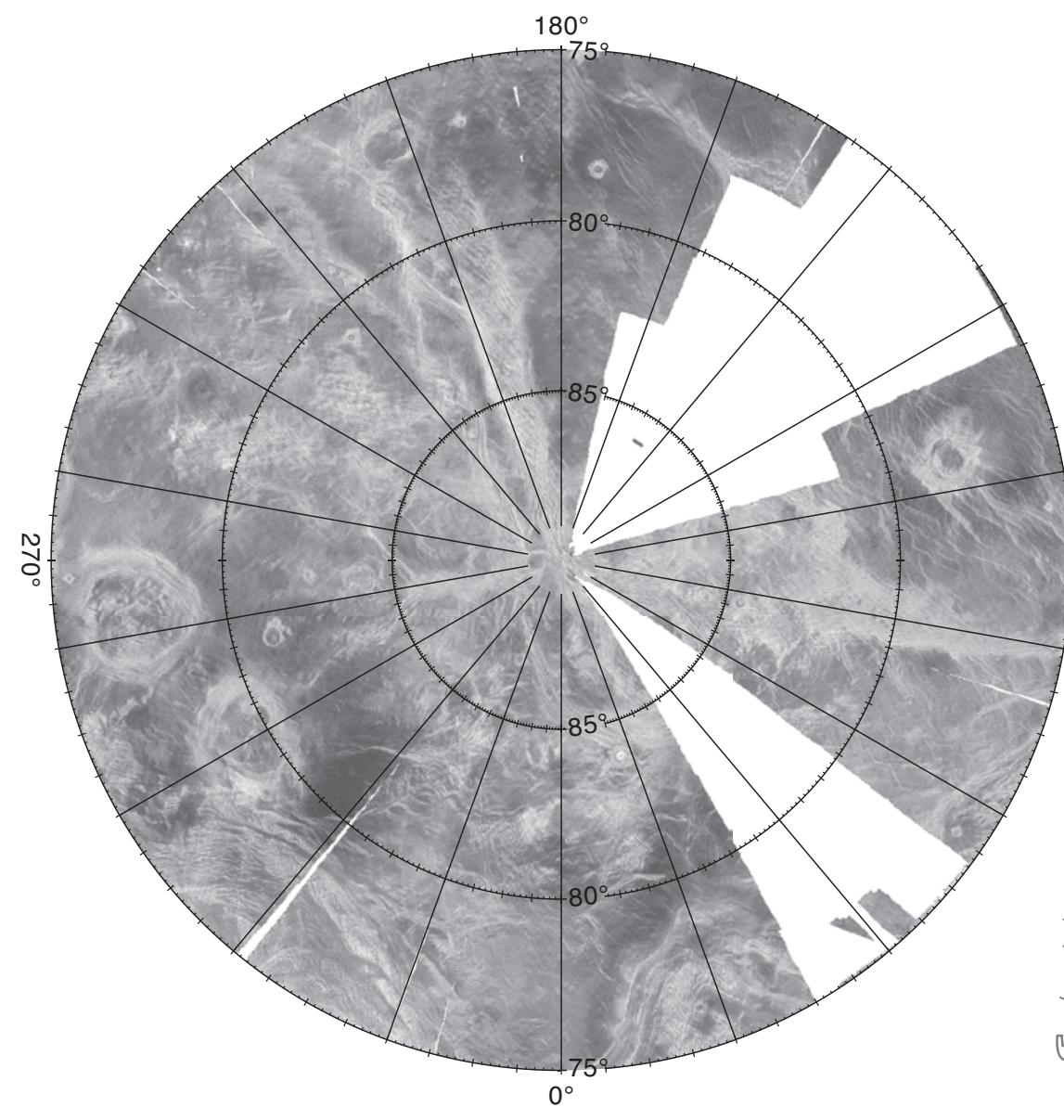

A

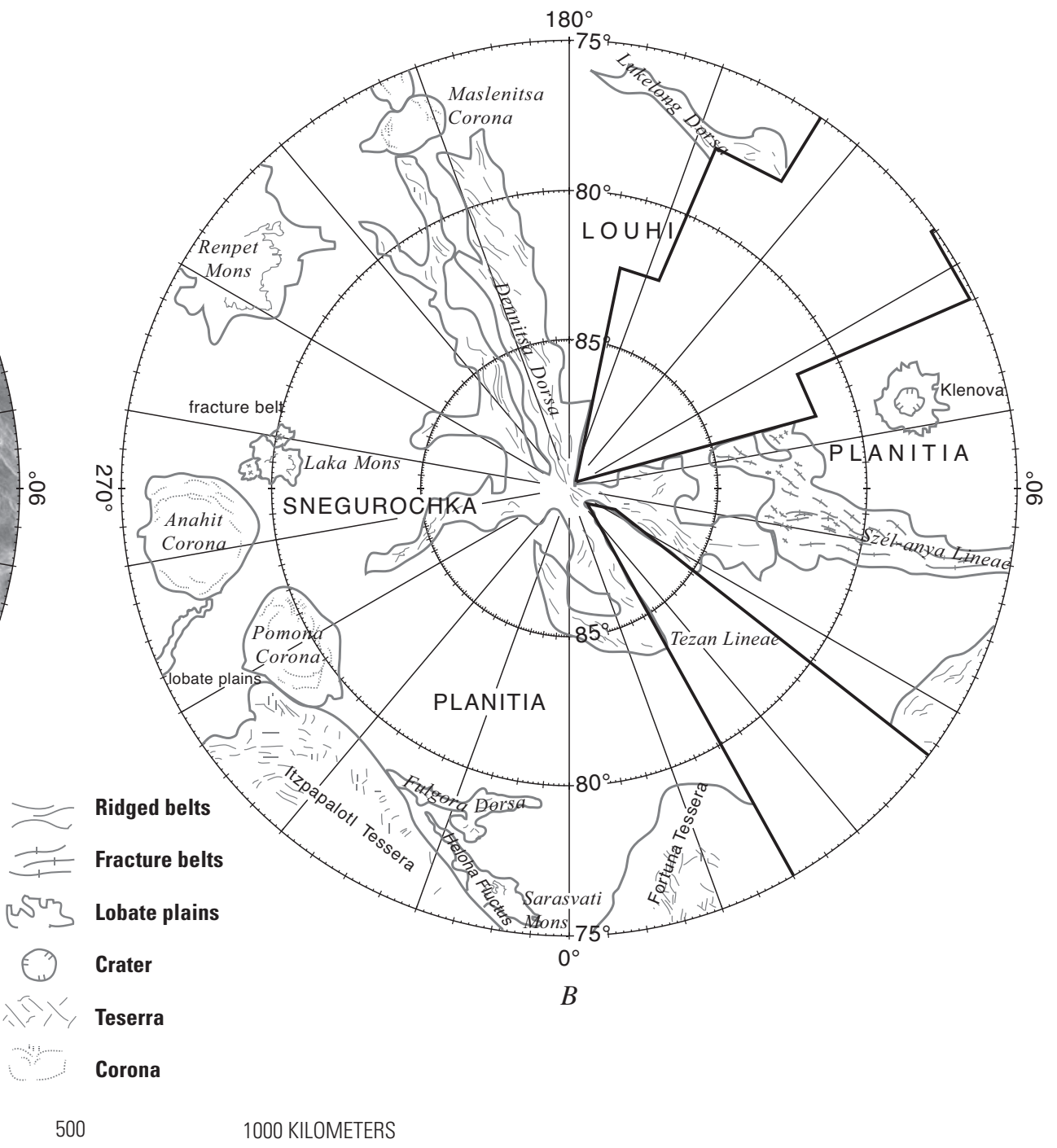

DOO KILOMETERS

Figure 1. $A$, Magellan synthetic aperture radar (SAR) data for Snegurochka Planitia, $\mathrm{V}-1$, Venus, from lat $75^{\circ} \mathrm{N}$. to $90^{\circ} \mathrm{N}$.; $B$, Geologic sketch of the $\mathrm{V}-1$ region with major tectonic and volcanic features labeled. 


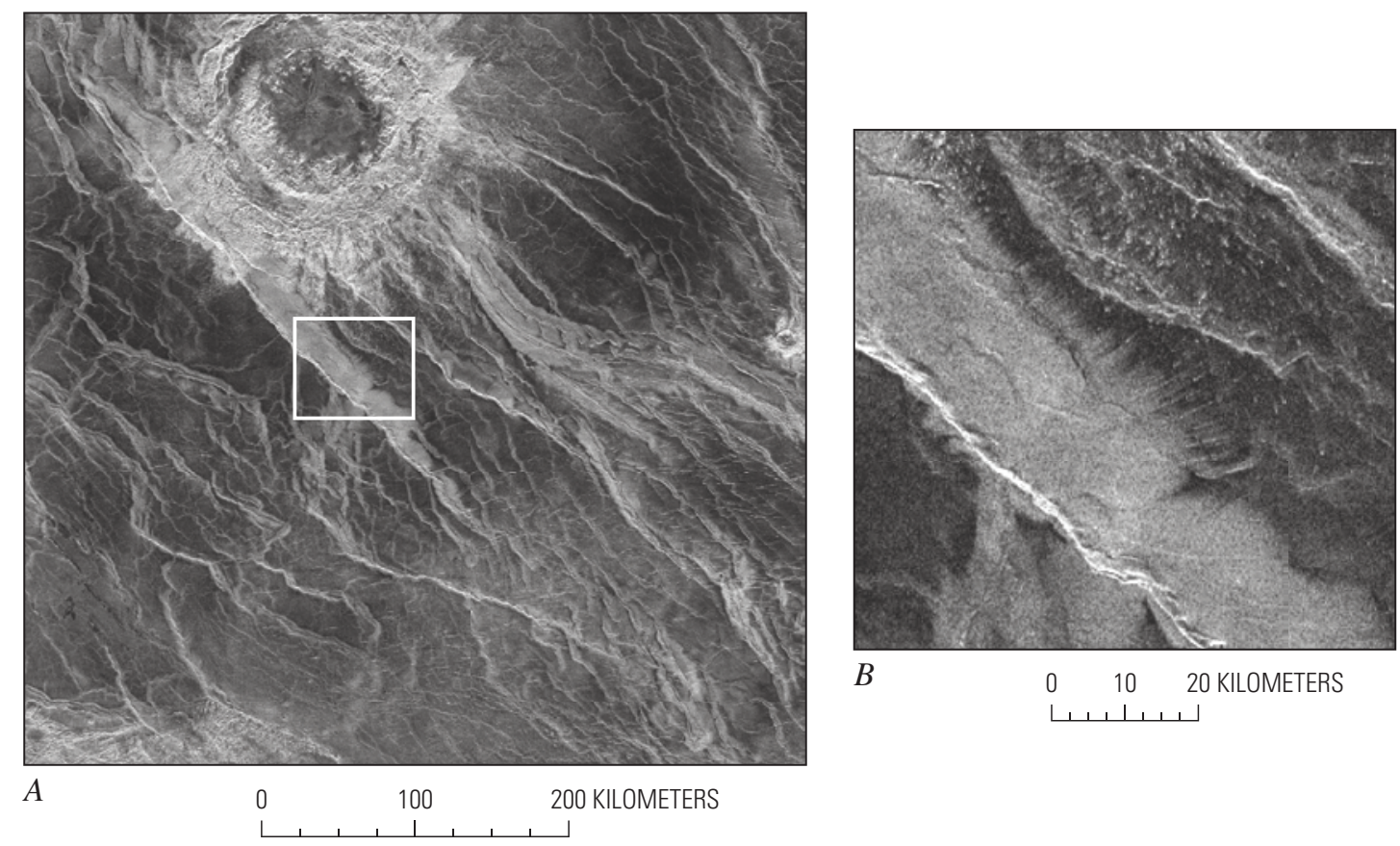

Figure 7. Regional plains near Klenova crater that have been extensively deformed by wrinkle ridges. $A$, This Magellan image, spanning from latitude $75^{\circ} \mathrm{N}$. to $80^{\circ} \mathrm{N}$. and from longitude $85^{\circ} \mathrm{E}$. to $109^{\circ} \mathrm{E}$., shows Klenova crater superposed on both radar dark plains and radar bright smooth plains units that are apparently associated with wrinkle ridges. Origin hypotheses for this radar bright material are discussed in the text. $B$, Detail of area in figure $7 A$. Evidence for local aeolian processes is seen in streaks on the edges of these radar bright deposits, but these streaks are not commonly seen in $\mathrm{V}-1$. 


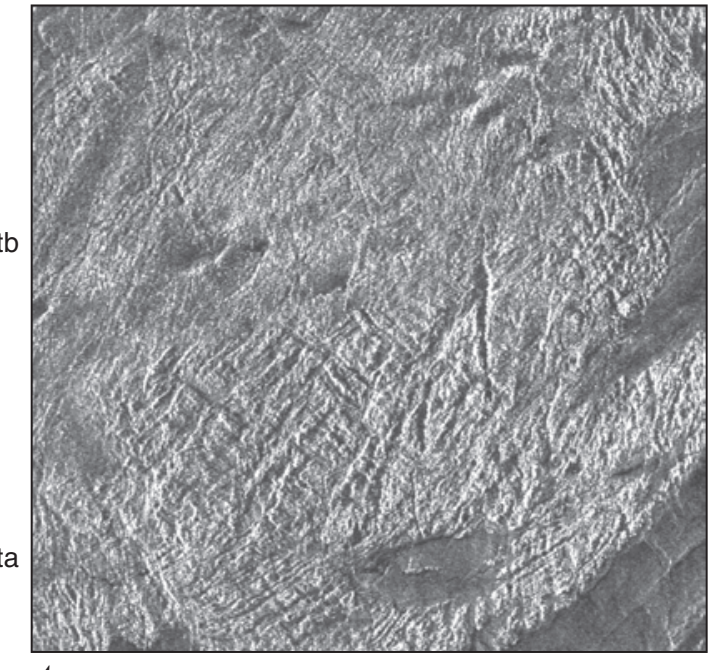

$A$

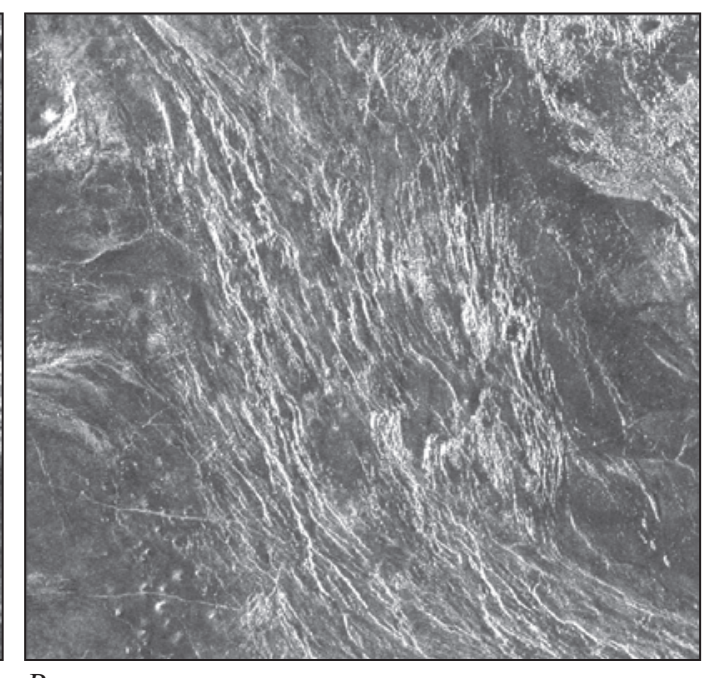

$B$

30

60 KILOMETERS

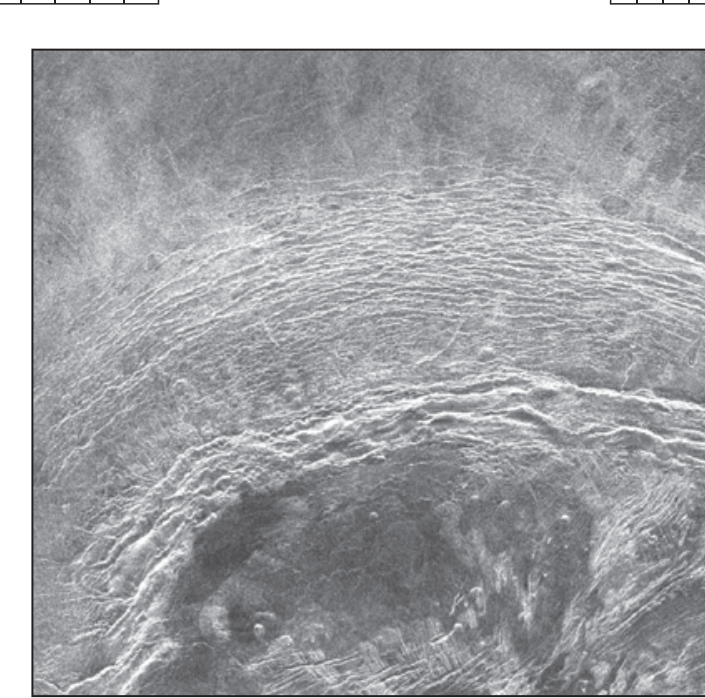

D

0

40

80 KILOMETERS

Figure 9. Examples of the heavily deformed units described in the text. $A$, Tessera unit ta clearly exhibits the two-directional deformation features that characterize tessera, while unit tb exhibits a slightly more subdued but still heavily folded deformation pattern. $B$, Densely lineated plains unit pdl exhibits the single direction of deformation, and the observed deposits generally have irregular boundaries with surrounding material. $C$, The ridged belt unit has a similar unidirectional deformation trend to the densely lineated plains unit, but

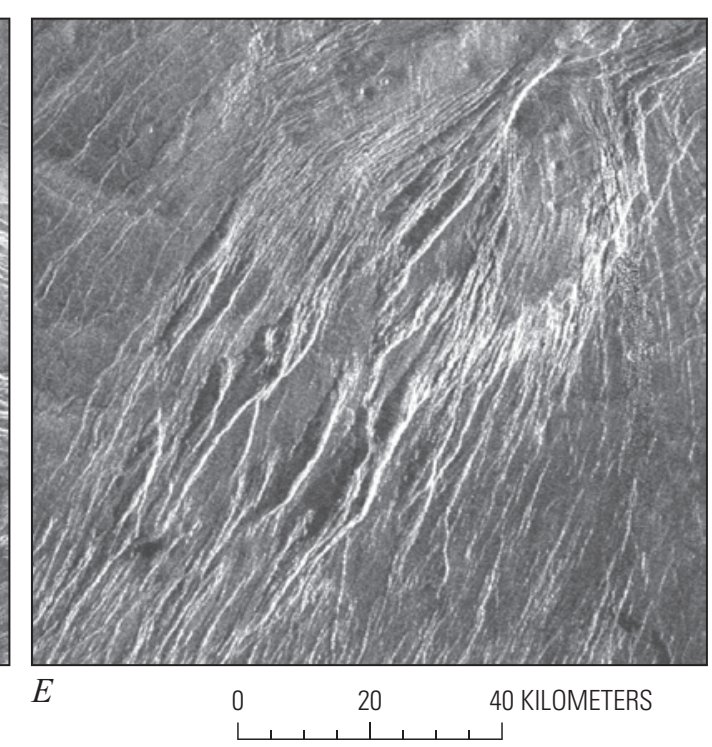

material in this unit appears as ridges confined to deformed belts that span the entire region of $\mathrm{V}-1$. $D$, In some cases, the direction of lineation orientation is curved, leading to the formation of nearly concentric lineaments identified as annulus unit an. The latter deposits are common in the deformed outer rims of coronae such as Anahit Corona shown in figure 9D. E, Deformation associated with the fracture belt unit $\mathrm{fb}$ also appears confined to belts, but the deformation appears to produce fractures and grabens rather than ridges. 

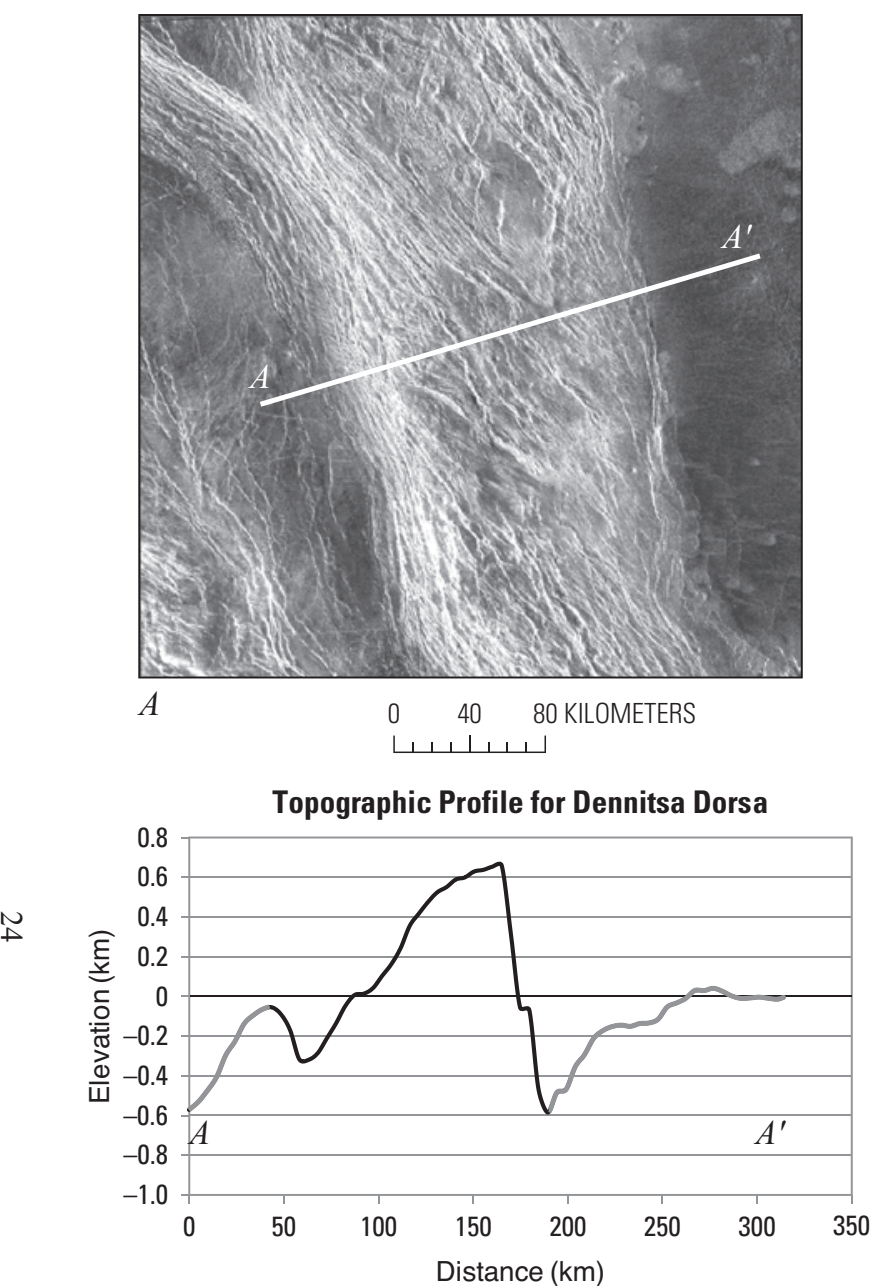
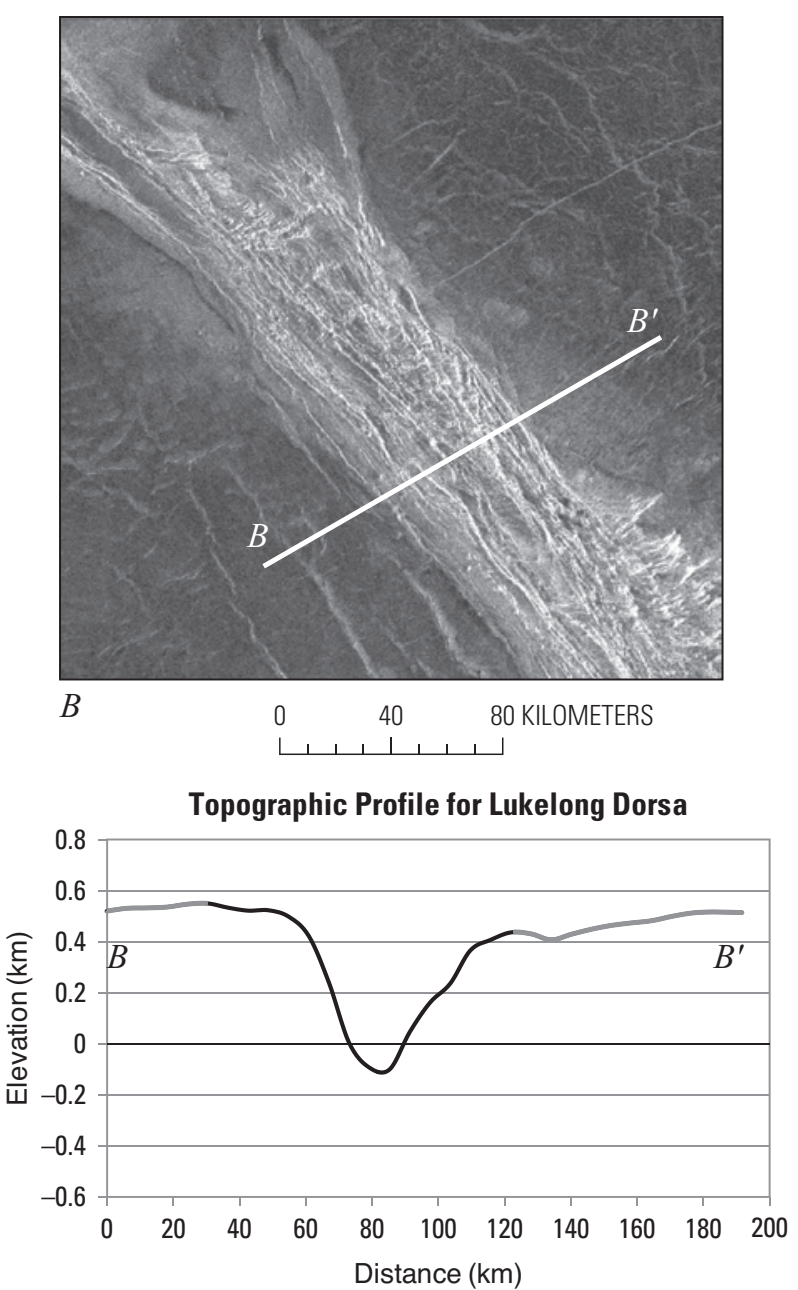

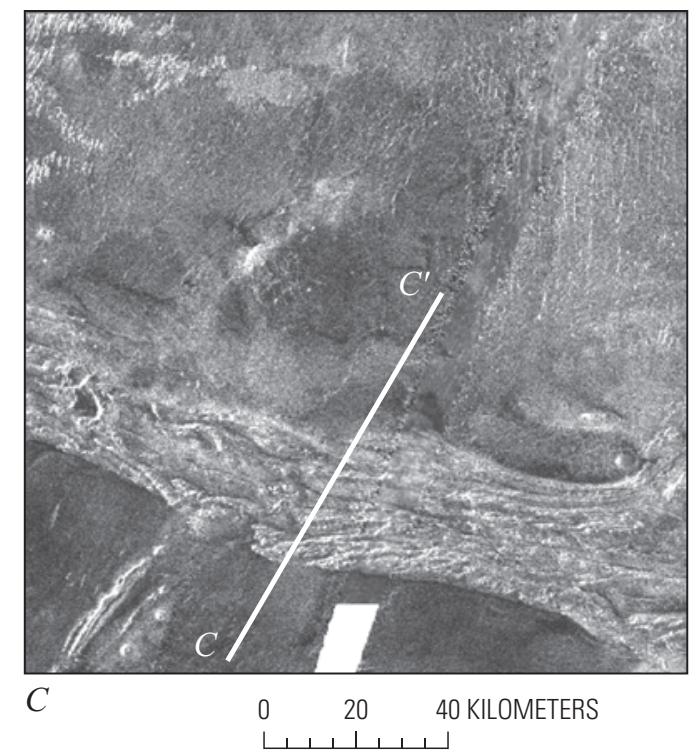

Topographic Profile for Fulgora Dorsa

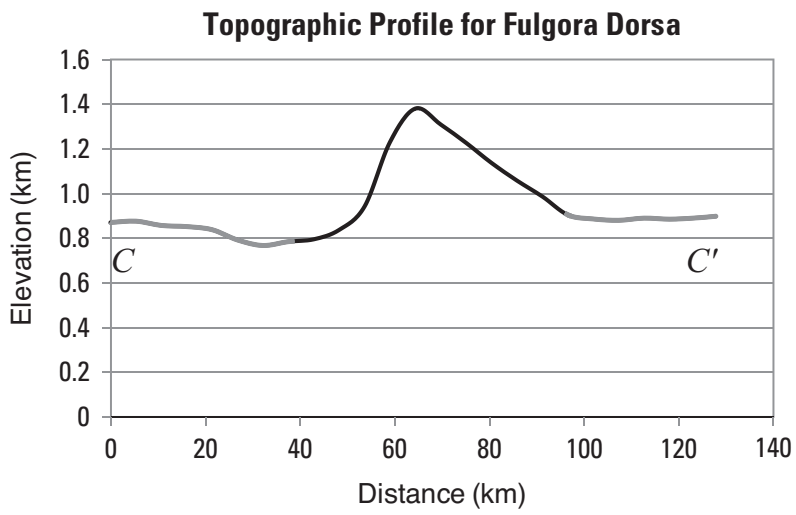

Figure 10. Topographic profiles of three ridged belts observed in $\mathrm{V}-1$, with the extent of each belt represented in bold on each profile. A, Dennitsa Dorsa appears to have troughs that parallel each side of the ridged belt. These troughs lie approximately $400 \mathrm{~m}-700 \mathrm{~m}$ below the adjacent plains while the ridged belt lies approximately $900 \mathrm{~m}$ above the plains. The plains appear to embay the ridged belt, at least partially covering the majority of the ridges that might splay into the surrounding areas. $B$, Lukelong Dorsa has a unique topographic profile, with the center of the belt forming a trough that lies $800 \mathrm{~m}$ below the

surrounding plains. These relatively young dark smooth regional plains have been substantially deformed by wrinkle ridges that generally parallel Lukelong Dorsa, possibly indicating a continuing compressive stress regime in the area perpendicular to the ridged belt. $C$, Fulgora Dorsa, near the topographic boundary between Itzpapalotl Tessera and Snegurochka Planitia, has a raised topographic signature, rising $600 \mathrm{~m}$ above the surrounding plains. The adjacent plains materials in this area appear to have embayed the ridged belt and lack evidence for significant deformation after emplacement. 

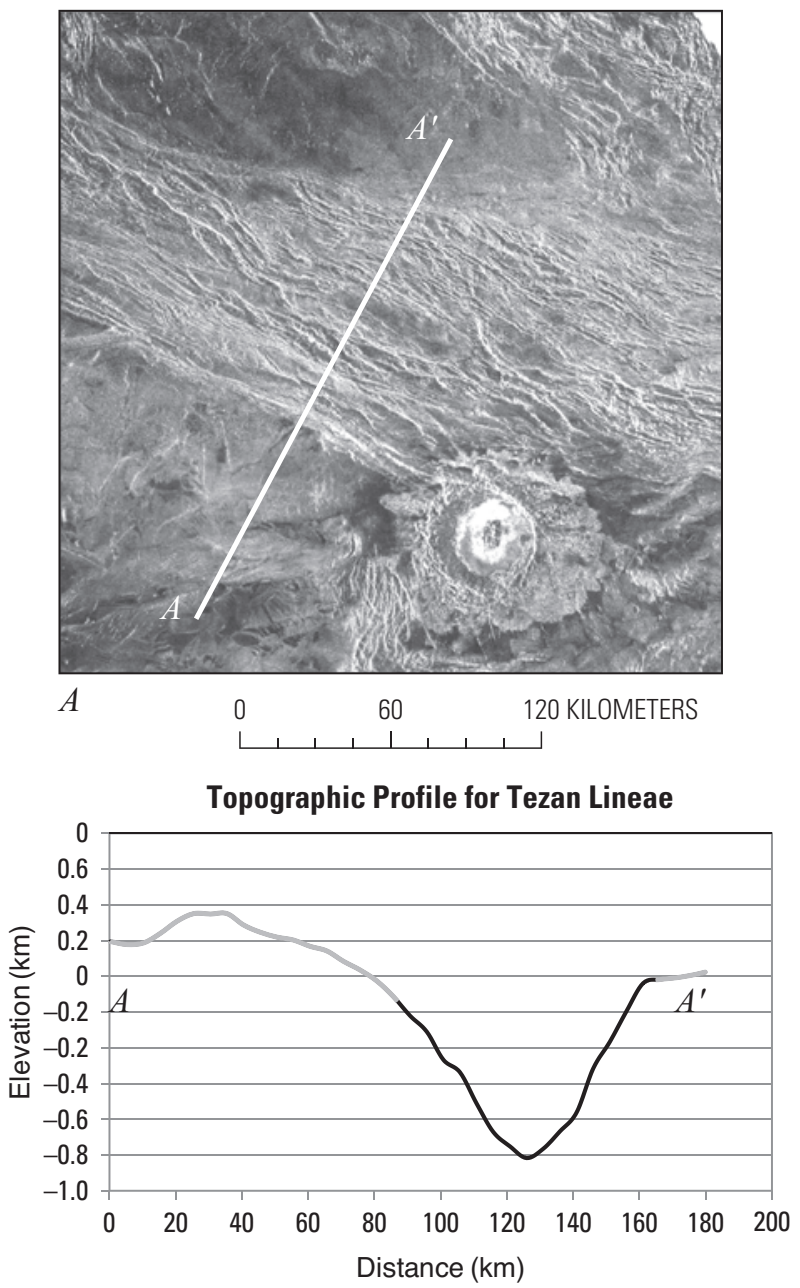
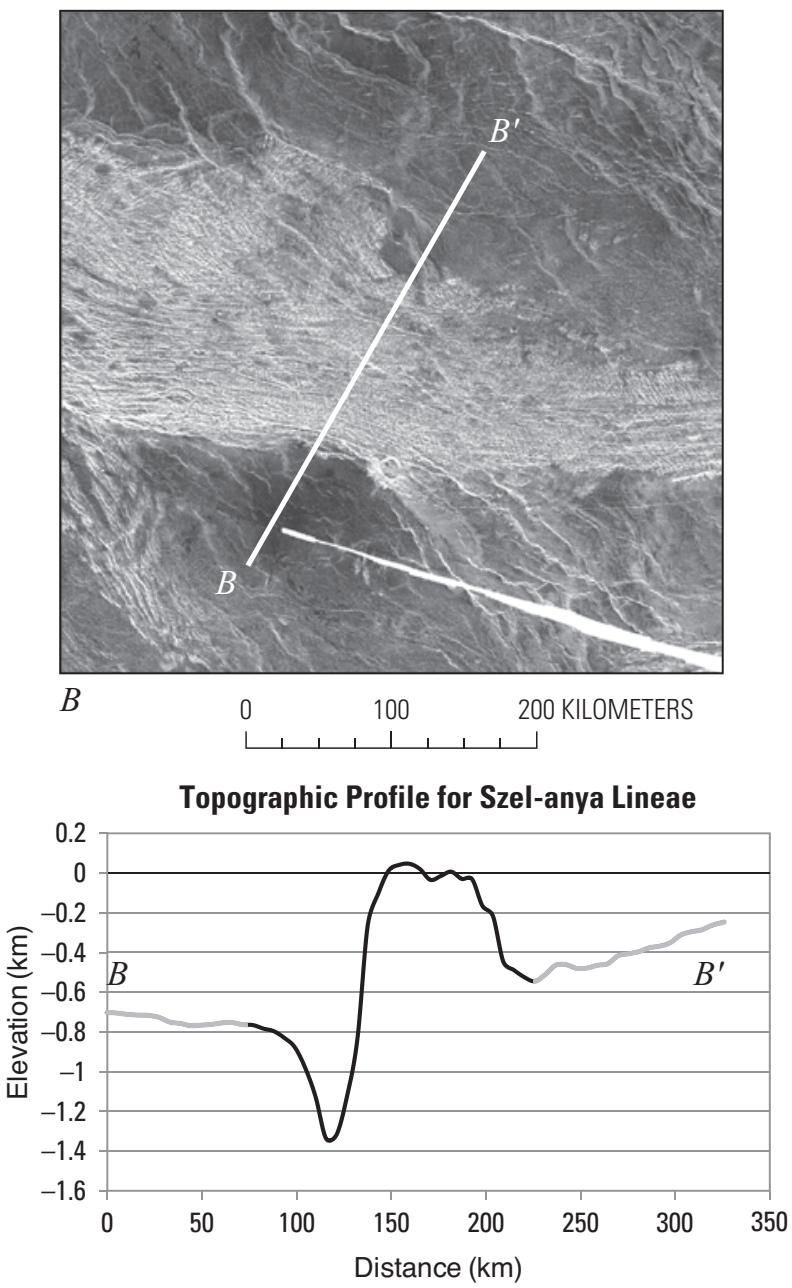

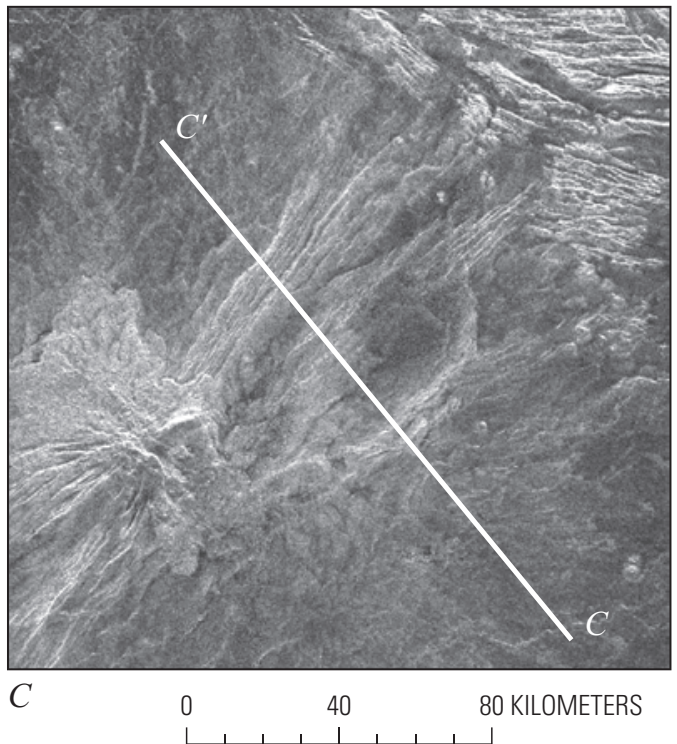

Topographic Profile for Laka Mons Fracture Belt

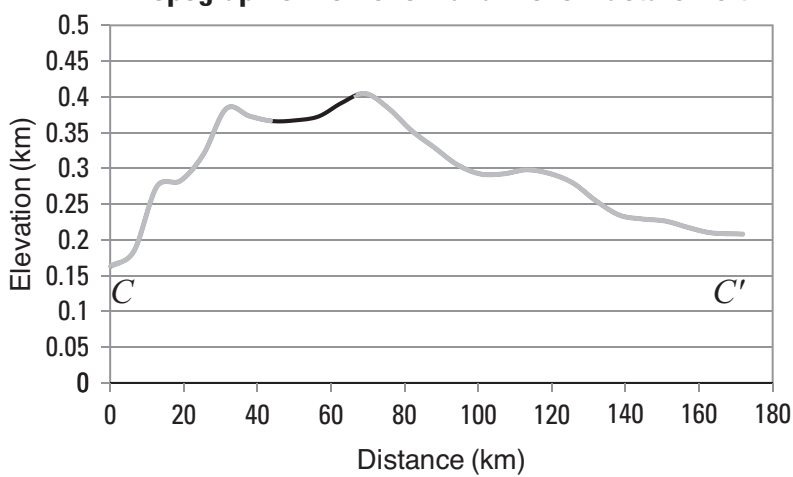

Figure 11. Topographic profiles of three fracture belts observed in $\mathrm{V}-1$, with the extent of each belt represented in bold on each profile. $A$, Tezan Lineae lies approximately $1 \mathrm{~km}$ below the adjacent plains units pdd, pbd, pds, and pbs $(\sim 1.4 \mathrm{~km}$ below MPR). These plains units appear to embay the belt of deformed material, and the relatively undeformed nature of the plains suggests that they are relatively young deposits. $B$, Szél-anya Lineae also is characterized by a trough that lies $\sim 700$ $\mathrm{m}$ below the surrounding plains $(\sim 1.3 \mathrm{~km}$ below MPR), and the terrain on the opposite side of the fracture belt is elevated $\sim 500-900 \mathrm{~m}$ above the surrounding plains ( $100 \mathrm{~m}$ above MPR). This elevated terrain is a local occurrence of tessera terrain that is apparently cut by fractures associated with the nearby fracture belt, indicating that the fracture belt is the younger feature. $C$, An unnamed fracture belt near the large shield volcano Laka Mons has a raised topographic signature, rising $200 \mathrm{~m}$ above the surrounding plains (400 $\mathrm{m}$ above MPR). The adjacent lobate plains unit pla in this area appear not only to have covered the fracture belt but also to be centered on the fracture belt, indicating that the lobate plains might have formed as a result of the formation of the fracture belt. 


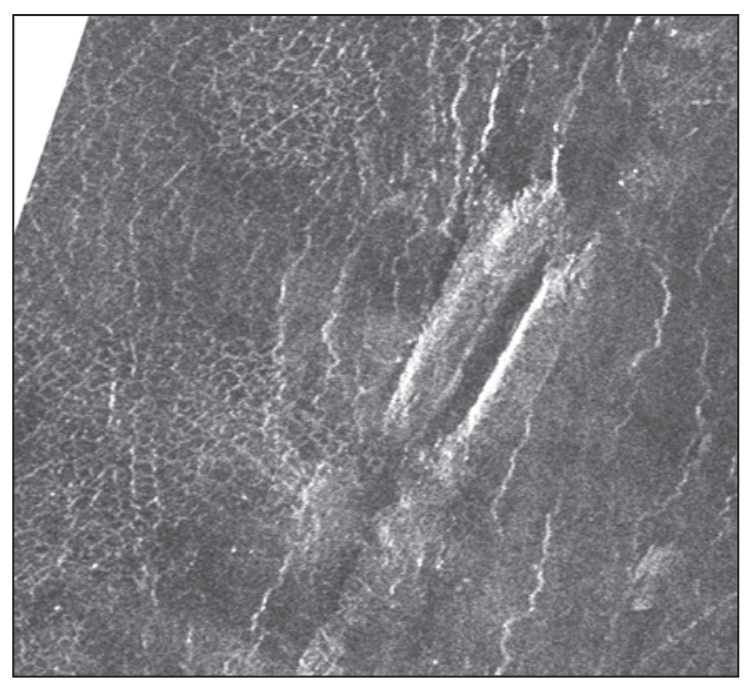

A

40

20 KILOMETERS

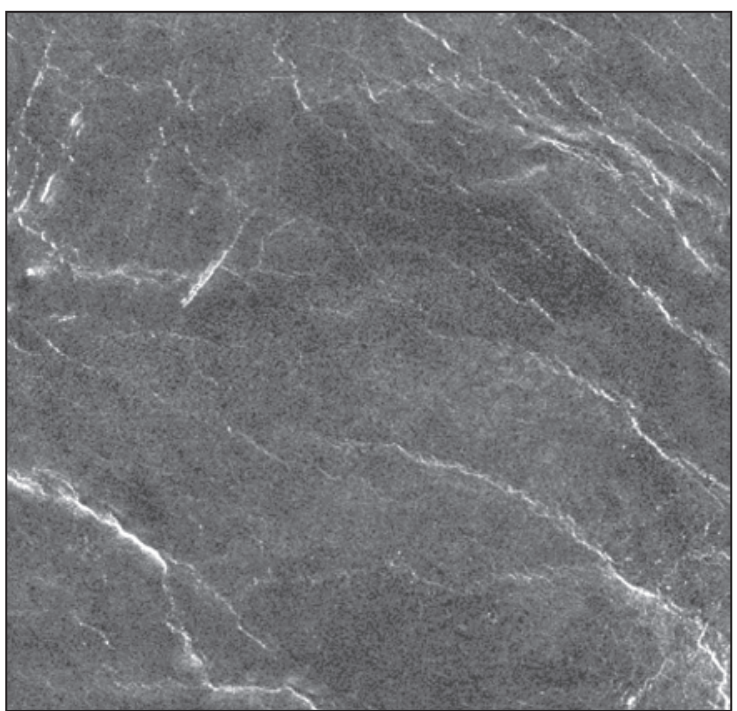

$C$
20

40 KILOMETERS

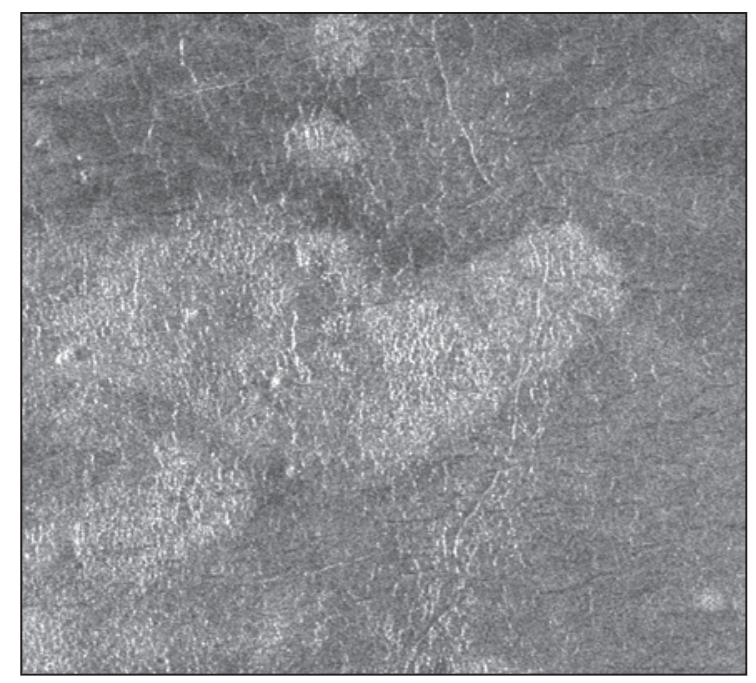

$B$

20

40 KILOMETERS

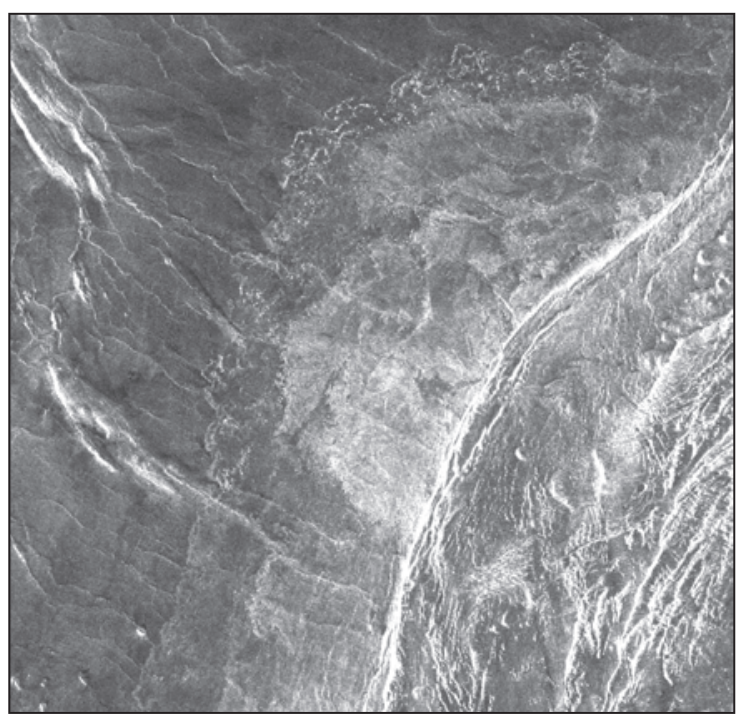

30

60 KILOMETERS

Figure 12. Examples of regional plains units described in the text. $A$, Dark deformed plains unit pdd has small-scale deformation in the form of polygonal cracks or ridges deforming radar dark plains; $B$, bright deformed plains unit pbd generally has a rougher texture with a hummocky or deformed appearance; $C$, dark smooth plains unit pds is the darkest unit in mapped in the region and are generally characterized by a very smooth, undeformed morphology, though subsequent regional tectonism does superpose these deposits with wrinkle ridges and grabens; and $D$, bright smooth plains unit pbs is generally observed in association with either a topographic barrier or a fissure, and this unit typically covers surrounding material in deposits of a relatively undeformed radar bright texture. 


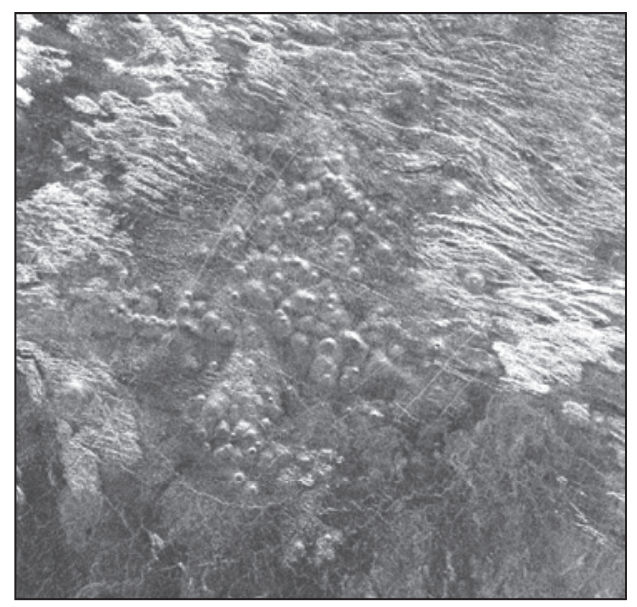

A

$0 \quad 20 \quad 40$ KILOMETERS

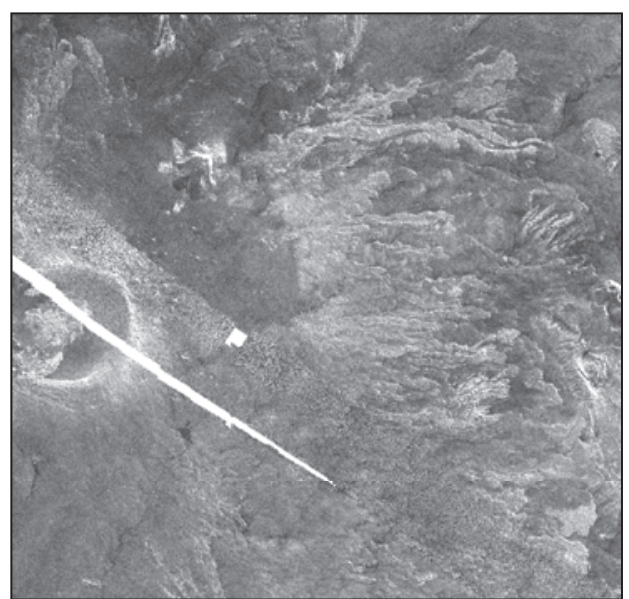

$D$

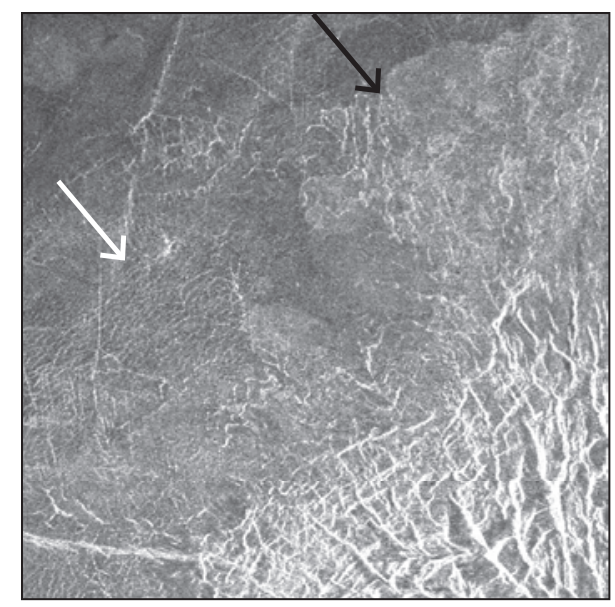

$B$

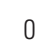

20

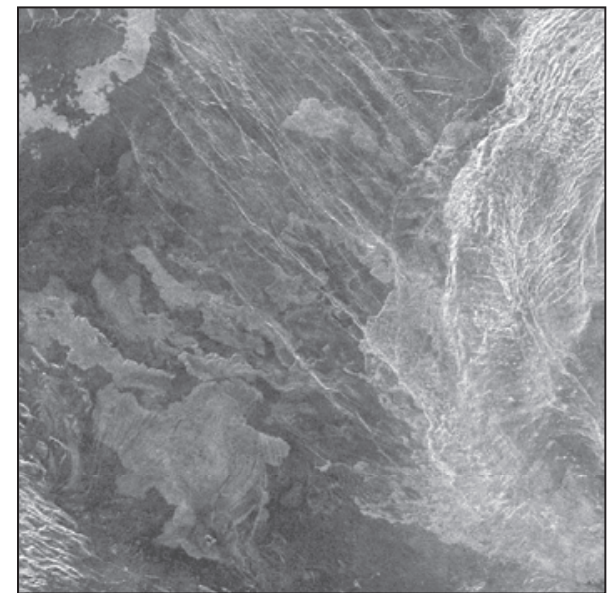

E

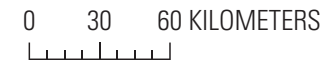

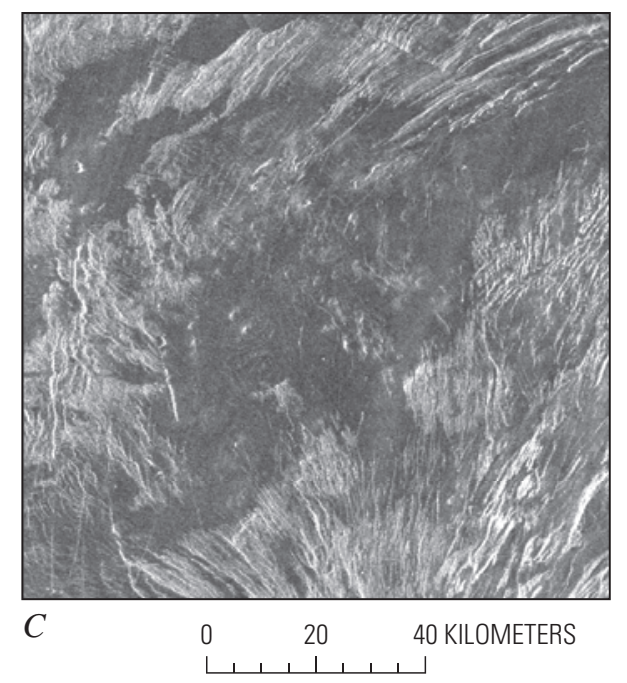

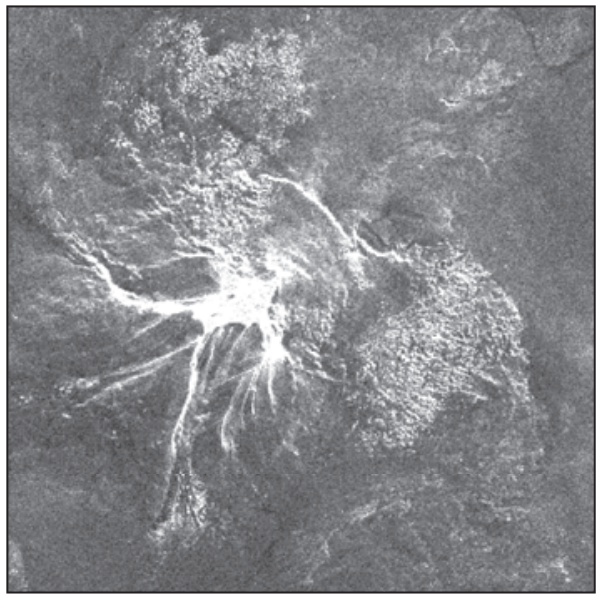

F
$0 \quad 10 \quad 20$ KILOMETERS
Figure 13. Examples of localized plains units described in the text. $A$, Both shield plains units $\mathrm{psh}_{1}$ and $\mathrm{psh}_{2}$ are characterized by clusters of radar bright aprons that surround bright central peaks and, in some cases, overlap. In this case, the aprons of the shields in the lower shield plains unit $\mathrm{psh}_{1}$ appear to embay the nearby deformed material but are partially covered by the adjacent regional plains units, a stratigraphic sequence that is generally observed throughout Venus. $B$, Radar bright deformed and smooth corona plains units (pcbd, left white arrow and pcbs, right black arrow, respectively) have relatively high radar backscatter, and the deformed plains have small-scale deformation in the form of local wrinkles and cracks while the smooth plains generally lack significant tectonic deformation at the available data resolution. $C$, The radar dark smooth corona plains unit (pcds) has relatively low radar backscatter and is typically made up of undeformed materials that embay more heavily deformed materials in the interior of the corona plateau (for example, units pdl, an, ta). The more local distribution of units pcbd, pcbs, and pcds in association with coronae distinguish these materials from the morphologically similar regional plains units (fig. 12). $D$, and $E$, Lobate plains units pla $(D)$ and plb $(E)$ have distinctive patterns of material that ends in a digitate morphology with radar bright edges. Unit pla, shown in $D$, generally extends down slope from a central peak or source region such as the circular depression shown (Renpet Mons), and unit plb, shown in $E$, generally extends from lineaments likely associated with propagating dikes that feed local surface eruptions. $F$, Edifices (unit ed) have extremely high radar backscatter characteristic of layover caused by steep slopes, and some edifices are also associated with bright hummocky material that appears to originate from the flanks of the edifice itself. 


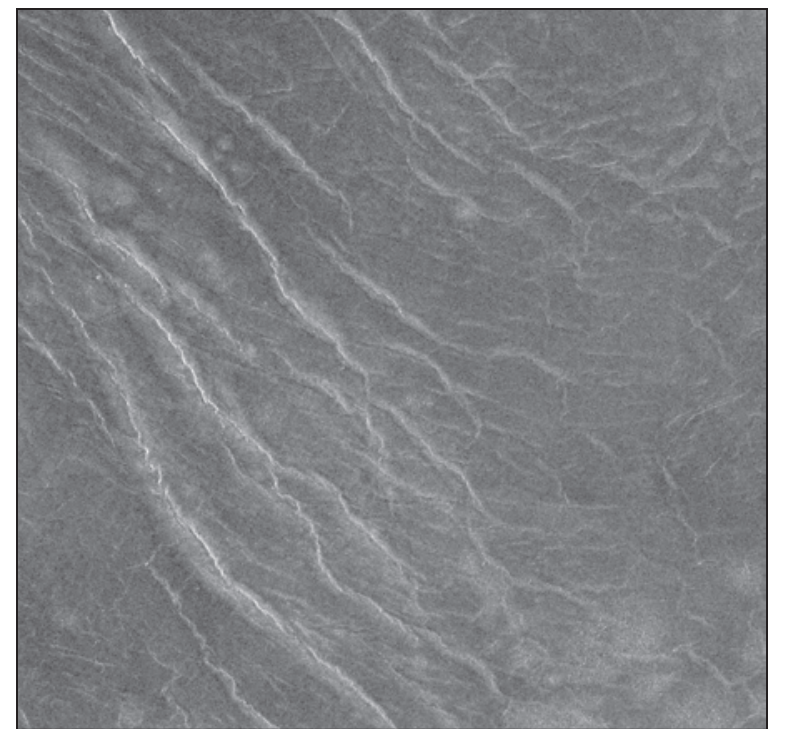

$D$
0
40
80 KILOMETERS

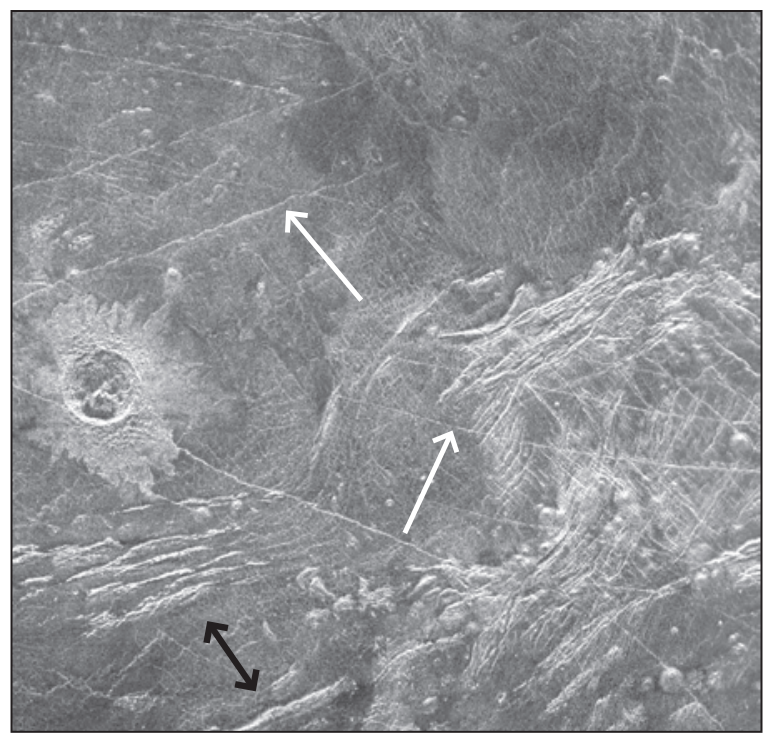

E

0

40

80 KILOMETERS

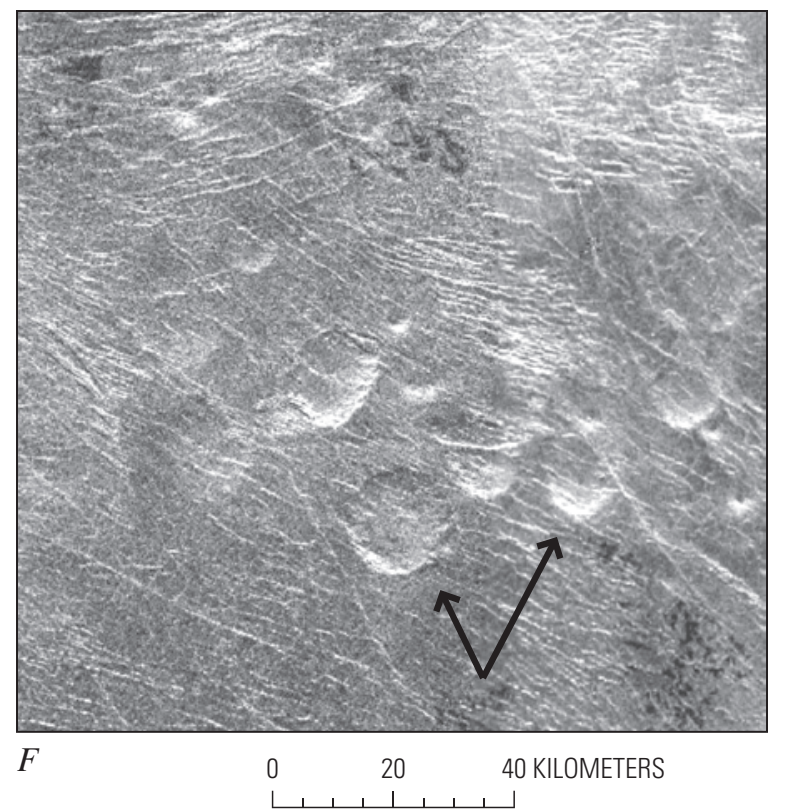

20

40 KILOMETERS

Figure 15. Examples of structures described in the text. $A$, Wrinkle ridges appear as radar bright ridges that generally deform underlying regional plains units in the presence of compressive stresses. $B$, Simple ridges (black arrows) are distinct from wrinkle ridges in that they have broader ridge crests and often cluster to form more heavily deformed geologic units. In contrast, lineaments (white arrows) appear as relatively straight features that cut across more tectonically deformed materials as well as regional plains features, though some lineaments are embayed by other regional plains deposits. $C$, Steep-sided domes, also referred to as "pancake domes" (black arrows), are characterized by steep edges bounding a broad, flat plateau, and they are commonly believed to form as the result of eruptions of viscous lavas. 